\title{
An Extended Spring-mass Model of Single-lap Multi- bolt Composite Joints Considering Assembly Gap and Gap Shimming
}

yuxing yang ( $\nabla$ yangyuxing@dlmu.edu.cn )

Dalian Maritime University https://orcid.org/0000-0002-6134-0514

\section{Yongjie Bao}

Dalian Maritime University

Jinlong Wang

Dalian Maritime University

Fengming Du

Dalian Maritime University

Original Article

Keywords: Spring-mass model, Multi-bolt joints stiffness, Assembly gap, Gap shimming

Posted Date: May 26th, 2021

DOl: https://doi.org/10.21203/rs.3.rs-541810/v1

License: (c) (i) This work is licensed under a Creative Commons Attribution 4.0 International License.

Read Full License 


\title{
An extended spring-mass model of single-lap multi-bolt composite joints considering assembly gap and gap shimming
}

\author{
Yuxing Yang, ${ }^{1, *}$ Yongjie Bao ${ }^{1, *}$, Jinlong Wang ${ }^{1}$, Fengming Du ${ }^{1}$ \\ ${ }^{1}$ Marine Engineering College, Dalian Maritime University, Dalian 116026, China.
}

\begin{abstract}
To investigate the effect of assembly gap and shim on single-lap multi-bolt composite joint stiffness, an analytical model based on the spring-mass method was proposed, which converted the multi-bolt joints into individual single-bolt joint based on premise that there are no overlap regions of the highly stressed portions for adjacent holes. The proposed model considers the conical and spherical stress envelope and gradual elimination phenomenon of the bolt-hole clearances for multi-bolt joints. Meantime, an effectiveto-equivalent gap area method was proposed to calculate the joint stiffness for situations with arbitrary assembly gap shape. Both experiment and finite element method for three-bolt joints were used to validate the proposed model with different situations of assembly gap and/or shim. The relative error of the shear stiffness between the analytical model and experiment is $0.31 \%$, while that of the bolt stiffness is $19.8 \%$. After that, four interested situations with different assembly gap and/or shims were discussed, and the maximum relative error of the shear stiffness between the analytical model and the finite element model is $17.0 \%$, while that of the bolt stiffness is $15.8 \%$. Taking into account the complexity of composite material and that of assembly gap and gap shimming, the proposed analytical model is effective to predict the stiffness of the single-lap multi-bolt composite joints subjected to single-shear loading.
\end{abstract}

Key words: Spring-mass model; Multi-bolt joints stiffness; Assembly gap; Gap shimming

\section{Introduction}

*Corresponding author:

E-mail: yongjie@dlmu.edu.cn (Yongjie Bao) yangyuxing@dlmu.edu.cn (Yuxing Yang) 
With the development of composite materials and its application in aerospace industry, more and more complicated composite parts are designed, which makes manufacturing accuracy guarantee more and more difficult in the assembling process. Therefore, assembly gap between the components to be assembled occurs during the assembly process because the shape distortion problems of the composite parts [1-4], which changes the load transfer and assembly stress conditions, even induces damages of the assembly components [5-7]. Most studies concentrate on the effect of assembly gap compensation, especially the effect of liquid shim thickness on the bearing behaviors [8-13]. However, there are few researches focusing on the assembly gap itself, like how assembly gap affect the bearing behavior and to what extent it can be. Zhai et al. [14] conducted an experimental study for single-lap single-bolt hybrid joint with considering the machined assembly gap. The results show that joint stiffness loss occurs earlier and peak load decreases as the assembly gap thickness increases. However, for multi-bolt joints, experimental method and finite element method are time-consuming and have their limitations to investigate the joint stiffness. Thus, a convenient analytical method need to be developed.

Spring-mass model is one of analytical methods to predict the joint stiffness. Tate et al. [15] firstly proposed the spring-mass method to study load distribution of the joints made by isotropic materials, and it was modified by Nelson et al. [16] to account for the single-lap orthotropic composite joints. Then, McCarthy et al. introduced the bolt-hole clearance [17] of the joints under highly preload [18] into the spring-mass model, and investigated the stiffness of the multi-bolt composite joints [18]; in addition, the slope of the first linear region in load-displacement curve before bolt-hole clearance was eliminated was named as the shear stiffness, while that of the second linear region after bolt-hole clearance has been eliminated, was named as the bolt stiffness [17]. Olmedo et al. [19, 20] developed an enhanced springmass model to account for the secondary bending effect of the bolt, which was based on the classic beam theory considering geometrical parameters, material properties, load path eccentricity and stacking sequence of the laminates. Yang et al. [21] extended the spring-mass model to the stiffness prediction for 
the single-lap single-bolt composite joints with considering assembly gap and gap shimming.

In this paper, a multi-bolt spring-mass model considering different assembly gap and/or shim, which was an extension of the Yang's model [21], was proposed to predict the shear stiffness and the bolt stiffness (named by McCarthy in reference [18]) of the single-lap multi-bolt composite joints. The conical and spherical envelope of the transverse shear stress as well as gradual elimination of the bolt-hole clearances for multi-bolt joints were considered and validated by three-bolt single-shear experiments. And effectiveto-equivalent gap area method was proposed to convert the arbitrary assembly gap shape to the basic circular shape. The finite element method (FEM) validated by the experiments was used as an assistant validation of the analytical method (AM) to discuss different assembly gap and/or shimming situations.

\section{Analytical model for joint stiffness}

In order to investigate the multi-bolt joints stiffness, a single-lap $n$-bolt composite joints $(n \geq 1)$ was selected as the research object, as shown in Fig. 1, whose geometry sizes were set referring to the ASTM D5961 [22]. In this model, basic assembly gap shape was assumed as a circular ring with assembly gap size $\Delta$ and assembly gap radius $r_{\Delta}$, any other assembly gap shape can be converted to the basic shape using the effective-to-equivalent gap area method (introduced later).

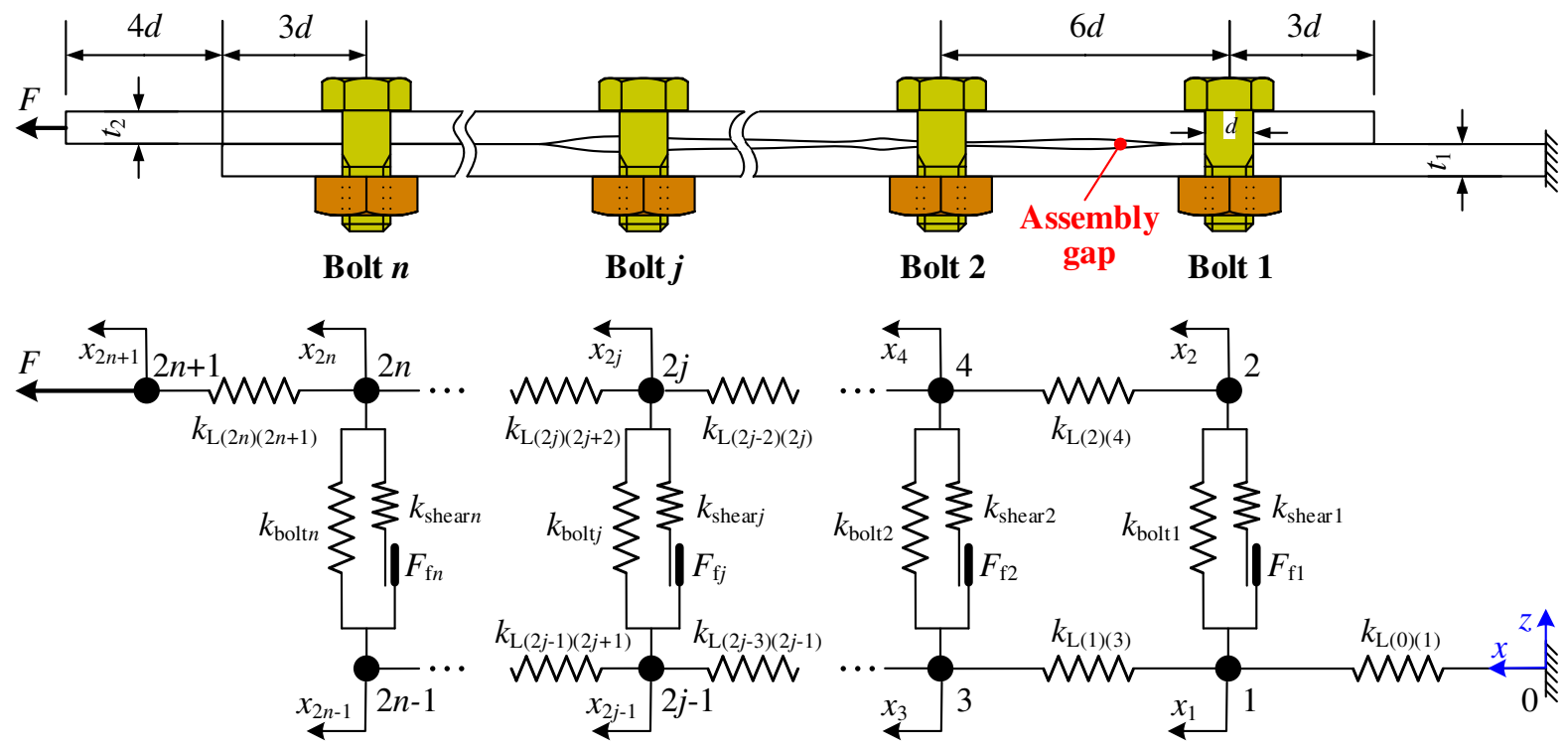

Fig. 1. Multi-bolt single-lap joints with assembly gap and its spring-mass system model. 
In Fig. 1 , totally $2 n+1$ particles (coded as $1,2, \ldots, 2 n+1$ ) are set to connect the springs; $F$ is the applied load; $x_{i}(i=1,2, \ldots, 2 n+1)$ represents the displacement along the loading direction for corresponding particles; $k_{\mathrm{L}}$ is the stiffness of the laminates between two adjacent bolts, e.g. subscript $(2 j)(2 j+2)$ means that the region of the laminated to be calculated is between the bolt $2 j$ and the bolt $2 j+2 ; k_{\text {shear }}(j=1,2, \ldots, n)$ is the shear stiffness corresponding to slope of the first linear region for each single-bolt joint, while $k_{\text {boltj }}(j=1,2, \ldots, n)$ is the bolt stiffness corresponding to slope of the second linear region for each singlebolt joint; $F_{\mathrm{f} j}(j=1,2, \ldots, n)$ represents the maximum static friction for each bolt, which is the product of the preload $F_{\mathrm{N} j}$ and friction coefficient $\mu$. The particles can only move in the $x$-direction. For example, diagrams of particle $2 j$ at the friction region and at the load take-up region (Fig. 2,) can be obtained by using the free-body diagrams and equations of motion [17, 18], as given in Eq. (1) and Eq. (2).

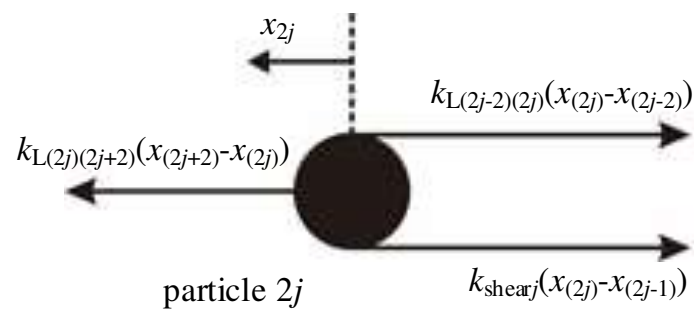

(a)

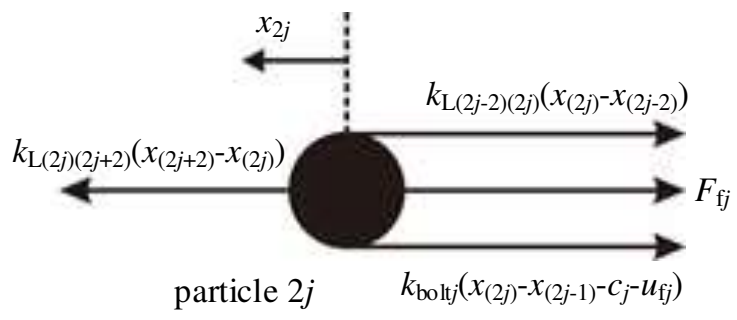

(b)

Fig. 2. Free-body diagrams of particle $2 j$ : (a) at friction region; (b) at load take-up region.

$$
\begin{gathered}
m a_{2 j}+k_{\mathrm{L}(2 j-2)(2 j)}\left(x_{(2 j)}-x_{(2 j-2)}\right)+k_{\text {shearj }}\left(x_{(2 j)}-x_{(2 j-1)}\right)-k_{\mathrm{L}(2 j)(2 j+2)}\left(x_{(2 j+2)}-x_{(2 j)}\right)=0 \\
m a_{2 j}+k_{\mathrm{L}(2 j-2)(2 j)}\left(x_{(2 j)}-x_{(2 j-2)}\right)+k_{\mathrm{boltj}}\left(x_{(2 j)}-x_{(2 j-1)}-c_{j}-u_{\mathrm{f}}\right)+F_{\mathrm{fj}}-k_{\mathrm{L}(2 j)(2 j+2)}\left(x_{(2 j+2)}-x_{(2 j)}\right)=0
\end{gathered}
$$

For quasi-static in-plane loading, the accelerations $a_{i}(i=1,2, \ldots, 2 n+1)$ of all the particles can be neglected so that dynamic equation can be expressed as the following equation [18], where $\mathbf{K}, \mathbf{x}, \mathbf{F}$ represent stiffness matrix, displacement vector and load vector.

$$
\mathbf{K x}=\mathbf{F}
$$




\subsection{Shear stiffness of the friction region}

At the first linear region in load-displacement curve (friction region), stiffness matrix, displacement vector and load vector can be expressed by Eq. (4) (6) [4], in which any particles except for the particle $(2 n+1)$ can be represented by particle $(2 j-1)$ and $(2 j)$ as long as $j \in[1, n]$ and $k_{\mathrm{L}(-1)(1)}=k_{\mathrm{L}(2 n)(2 n+2)}=0$ were satisfied. The ellipsis dots in Eq. (4) represent other matrix elements, which have similar forms.

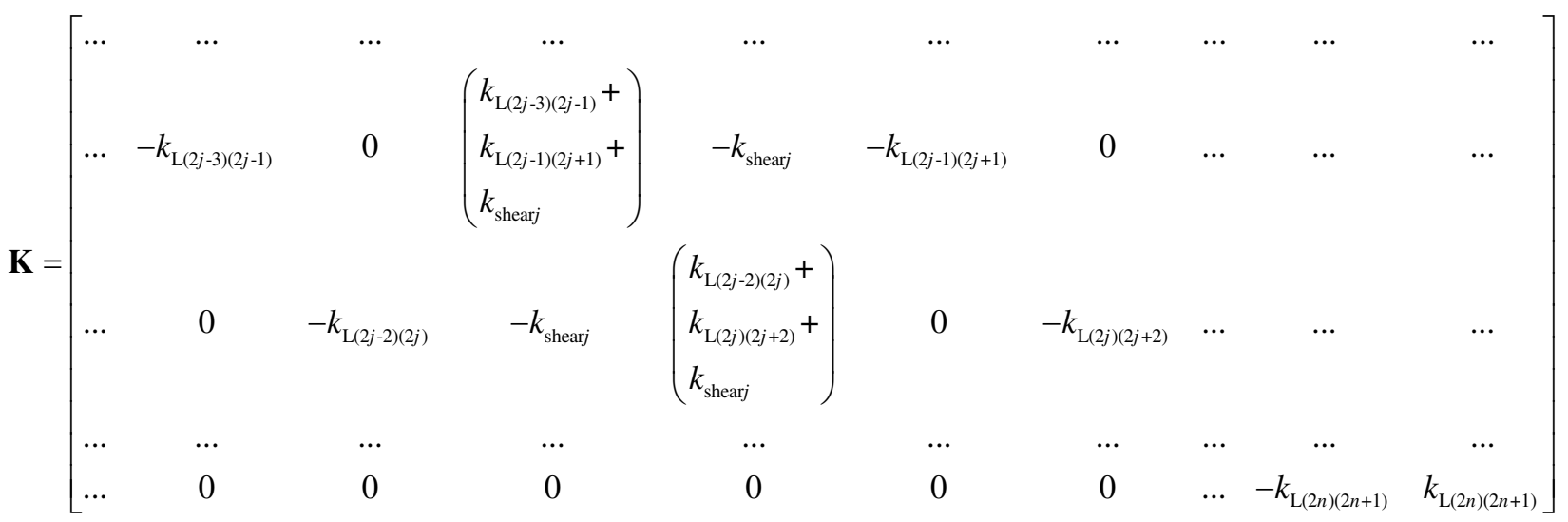

$$
\begin{aligned}
& \mathbf{x}=\left[x_{1}, x_{2}, \ldots, x_{(2 n+1)}\right]^{\mathrm{T}} \\
& \mathbf{F}=\left[0,0, \ldots, 0, F_{(2 n+1)}\right]^{\mathrm{T}}
\end{aligned}
$$

The laminate stiffness $k_{\mathrm{L}}$ can be calculated by Eq. (7) referring to [18, 19], where $E_{\mathrm{L} i}$ is the equivalent longitudinal elasticity modulus; $W$ and $t$ are width and thickness of the laminate; $p$ is the hole pitch between two adjacent holes or the distance between the hole center and the plate free end where load is applied for the holes on both sides; $d$ is hole diameter [21].

$$
\left\{\begin{array}{l}
k_{\mathrm{L}(0)(1)}=\frac{E_{\mathrm{L}} \cdot W \cdot t}{p-d / 2} \\
k_{\mathrm{L}(2 j)(2 j+2)}=\frac{E_{\mathrm{L}} \cdot W \cdot t}{p-d}(j \in[1, n-1]) \\
k_{\mathrm{L}(2 n)(2 n+1)}=\frac{E_{\mathrm{L}} \cdot W \cdot t}{p-d / 2}
\end{array}\right.
$$

In this study, only general situations that radius of the highly stressed portion is less than half of the 
hole pitch $(\gamma d) / 2+t \tan (\alpha) \leq 3 d$ are discussed, which means that there were no overlap regions of the highly stressed portions for adjacent holes. In other words, ratio of the hole diameter to the laminate thickness should meet $d / t \geq \tan (\alpha) /(3-\gamma / 2)$. As recommended in literature [23], $\gamma$ is the contact radii ratio $(\gamma=1.5)$, and $\alpha$ is the pressure distribution angle $\left(\alpha=30^{\circ}\right)$. Based on the assumption that the transverse shear stress $\tau_{x z}$ for single-bolt joint has the conical and spherical envelope [21], transverse shear stress envelope for multi-bolt joints can be described as independent single-bolt joints, as illustrated in Fig. 3.

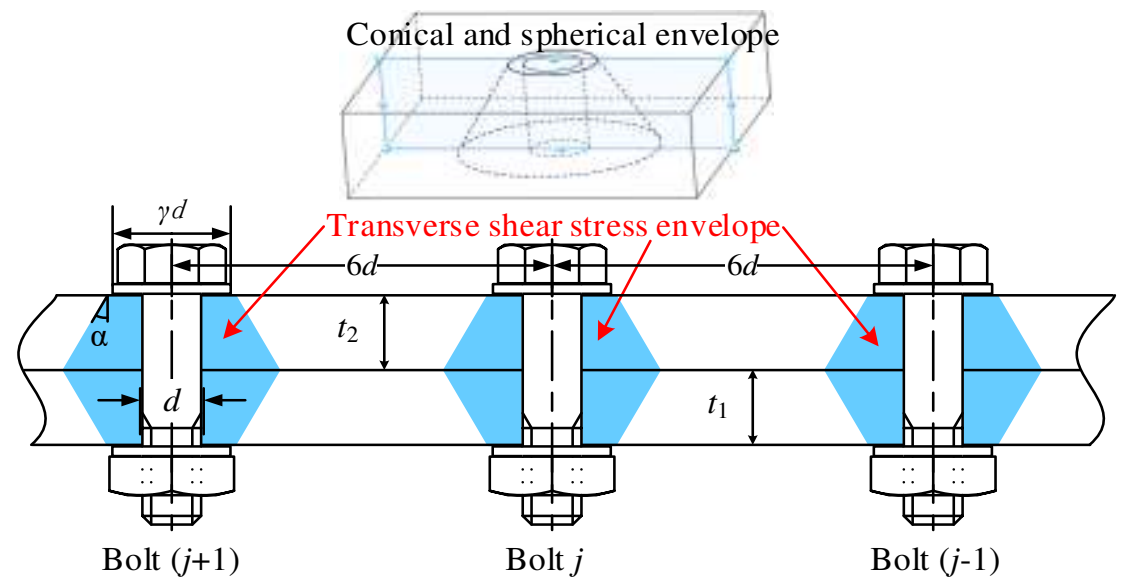

Fig. 3. Supposed transverse shear stress envelope of the multi-bolt joints.

For each single-bolt joint, shear stiffness $k_{\text {shear }}(j=1,2, \ldots, n)$ consists of the shear stiffness of the lower laminate $k_{\mathrm{shj-1}}(j=1,2, \ldots, n)$ and that of the upper laminate $k_{\mathrm{shj}-2}(j=1,2, \ldots, n)$ [19], as given in Eq. (8).

$$
\frac{1}{k_{\text {shear } j}}=\frac{1}{k_{\mathrm{sh} j-1}}+\frac{1}{k_{\mathrm{sh} j-2}}(j=1,2, \ldots, n)
$$

For transverse shear, elastic strain energy $U_{i}$ for a volume of material in laminate $i$ may be described by Eq. (9) [18], where $V, G_{\mathrm{xz}(i)}$ and $A_{\mathrm{e} i}$ are volume of the material with highly shear stressed portion, out-of-plane shear modulus and in-plane effective area. 


$$
U_{i}=\int_{V} \frac{\tau_{\mathrm{xz}}^{2} d V}{2 G_{\mathrm{xz}(i)}}=\frac{F_{\mathrm{f}}^{2}}{2 G_{\mathrm{xz}(i)}} \int_{0}^{t_{i}} \frac{d z}{A_{\mathrm{e} i}(z)}(i=1,2)
$$

As shown in Eq. (10), shear stiffness of the laminate $k_{\mathrm{shj}-i}$ is the ratio of friction force to deformation of the laminate $i$. In-plane effective area $A_{\mathrm{e} i}$, which satisfies conical and spherical envelope through the thickness (Fig. 4), changes as the assembly gap geometry or shimming conditions change.

$$
k_{\mathrm{sh} j-i}=\frac{F_{\mathrm{f}}}{\delta_{i}}=\frac{F_{\mathrm{f}}}{d U_{i} / d F_{\mathrm{f}}}=\frac{G_{\mathrm{xz}(i)}}{\int_{0}^{t_{i}} \frac{d z}{A_{\mathrm{e} i}(z)}} \quad(j=1,2, \ldots, n ; i=1,2)
$$

(a) For single-bolt joint without assembly gap, Fig. 4(a), in-plane effective area $A_{\mathrm{e}}$ can be calculated by Eq. (11) so that shear stiffness of the laminates $k_{\mathrm{sh} j-i}$ can be expressed by Eq. (12).

$$
\begin{gathered}
A_{\mathrm{e}}(z)=\pi\left[\left(\frac{\gamma d}{2}+z \tan \alpha\right)^{2}-\left(\frac{d}{2}\right)^{2}\right] \\
k_{\mathrm{sh}-i}=\frac{G_{\mathrm{xz}(i)} \pi d \tan \alpha}{\ln \left[\frac{2(\gamma+1) t_{i} \tan \alpha+\left(\gamma^{2}-1\right) d}{2(\gamma-1) t_{i} \tan \alpha+\left(\gamma^{2}-1\right) d}\right]} \quad(j=1,2, \ldots, n ; i=1,2)
\end{gathered}
$$

(b) For single-bolt joint with assembly gap, Fig. 4(b), the in-plane effective area can be divided into two parts: one is the laminate region without gap in the interval $z \in[0, t]$, which is described by in-plane effective area $A_{\text {en }}(z)$; and the other is the laminate region with gap marked by section lines in the interval $z \in(t, t+\Delta / 2]$, which is described by in-plane effective area $A_{\mathrm{eg}}(z)$. The shear stiffness of the laminates $k_{\mathrm{shj}-i}$ can be expressed by Eq. (15).

$$
\begin{aligned}
& A_{\mathrm{en}}(z)=\pi\left[\left(\frac{\gamma d}{2}+z \tan \alpha\right)^{2}-\left(\frac{d}{2}\right)^{2}\right] \\
& A_{\mathrm{eg}}(z)=\pi\left[\left(\frac{\gamma d}{2}+z \tan \alpha\right)^{2}-\left(r_{\Delta}\right)^{2}\right]
\end{aligned}
$$




$$
k_{\mathrm{sh} j-i}=\frac{G_{\mathrm{xz}(i)}}{\int_{0}^{t_{i}} \frac{d z}{A_{\mathrm{en}}(z)}+\int_{t_{i}}^{t_{i}+\Delta / 2} \frac{d z}{A_{\mathrm{eg}}(z)}}(j=1,2, \ldots, n ; i=1,2)
$$

(c) For single-bolt joint with shim 'situation (a)', Fig. 4(c), the in-plane effective area can be divided into three parts: the first part is the laminate region without gap in the interval $z \in[0, t]$, which is described by in-plane effective area $A_{\mathrm{en}}(z)$; the second part is the laminate region with gap marked by section lines in the interval $z \in(t, t+\Delta / 2]$, the in-plane effective area can be approximated to a constant value $\overline{A_{\mathrm{eg}}}$ (the assembly gap can be regarded as a rectangle shape considering that gap size is small); the third part is the shimming region with green color in interval $z \in(t, t+\Delta / 2]$, which is described by in-plane effective area $A_{\mathrm{es}}$, where $G_{\text {shim }}$ is the transverse shear modulus of the shim, $r_{\mathrm{s} 1}$ is the internal diameter of the shim, $r_{\mathrm{s} 2}$ is the external diameter of the shim, and it satisfies that $r_{\mathrm{s} 2} \geq r_{\mathrm{s} 1} \geq d / 2$. The shear stiffness of the laminates $k_{\mathrm{shj}-i}$ can be expressed by Eq. (19).

$$
\begin{gathered}
A_{\mathrm{en}}(z)=\pi\left[\left(\frac{\gamma d}{2}+z \tan \alpha\right)^{2}-\left(\frac{d}{2}\right)^{2}\right] \\
\overline{A_{\mathrm{eg}}}=\pi\left[\left(\frac{\gamma d}{2}+\left(t_{i}+\frac{\Delta}{2}\right) \tan \alpha\right)^{2}-r_{\Delta}^{2}\right](i=1,2) \\
k_{\mathrm{shj}-i}=\frac{A_{\mathrm{es}}=\pi\left[\left(r_{\mathrm{s} 2}\right)^{2}-\left(r_{\mathrm{s} 1}\right)^{2}\right]}{\frac{1}{G_{\mathrm{xz}(\mathrm{i})}}\left(\int_{0}^{t_{i}} \frac{d z}{A_{\mathrm{en}}(z)}+\left(\frac{\overline{A_{\mathrm{eg}}}}{\overline{A_{\mathrm{eg}}}+A_{\mathrm{es}}}\right)^{2} \int_{t_{i}}^{t_{i}+\Delta / 2} \frac{d z}{A_{\mathrm{eg}}(z)}\right)+\frac{A_{\mathrm{es}} \Delta}{2 G_{\mathrm{shim}}\left(\overline{A_{\mathrm{eg}}}+A_{\mathrm{es}}\right)^{2}}}(j=1,2, \ldots, n ; i=1,2)
\end{gathered}
$$

(d) For single-bolt joint with shim 'situation (b)', Fig. 4(d), the in-plane effective area can be divided into two parts: the first part is the laminate region without gap in the interval $z \in[0, t]$, which is 
described by in-plane effective area $A_{\mathrm{en}}(z)$; the second part is the shimming region with green color in interval $z \in(t, t+\Delta / 2]$, which is described by in-plane effective area $A_{\mathrm{es}}$. If the shim radius $r_{\mathrm{s} 2}$ exceeds the boundary of the highly stressed portion, it should be substituted by the radius of the highly stressed portion.. The shear stiffness of the laminates $k_{\mathrm{sh} j-i}$ can be expressed by Eq. (22).

$$
\begin{gathered}
A_{e n}(z)=\pi\left[\left(\frac{\gamma d}{2}+z \tan \alpha\right)^{2}-\left(\frac{d}{2}\right)^{2}\right] \\
A_{e s}=\pi\left[\left(r_{s 2}\right)^{2}-\left(r_{s 1}\right)^{2}\right] \\
k_{\mathrm{shj}-i}=\frac{1}{\frac{1}{G_{\mathrm{xz}(i)}} \int_{0}^{t} \frac{d z}{A_{\mathrm{en}}(z)}+\frac{\Delta}{2 G_{\mathrm{shim}} A_{\mathrm{es}}}}(j=1,2, \ldots, n ; i=1,2)
\end{gathered}
$$

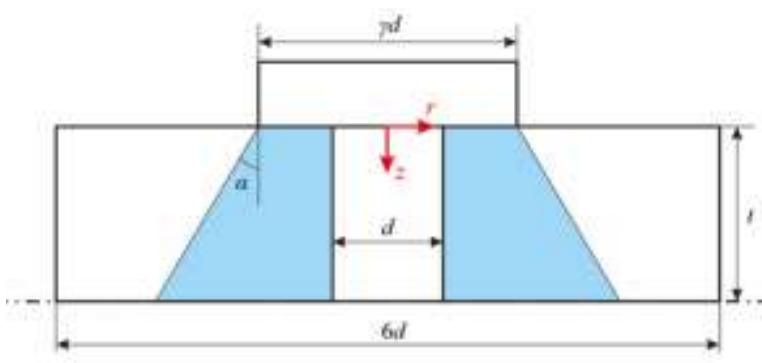

(a)

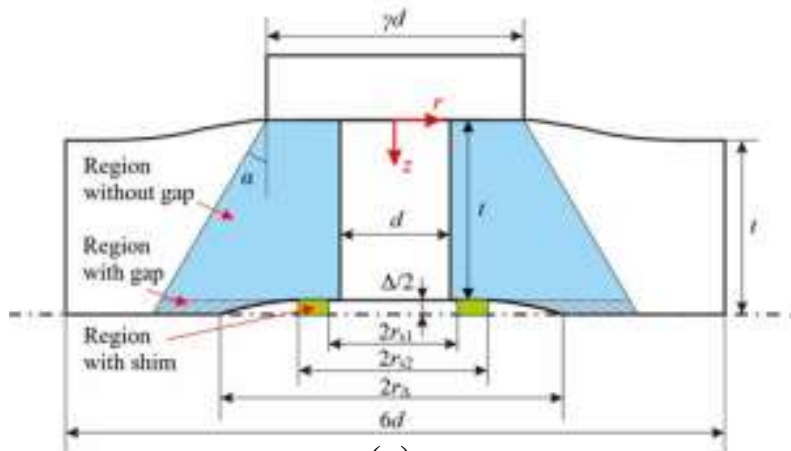

(c)

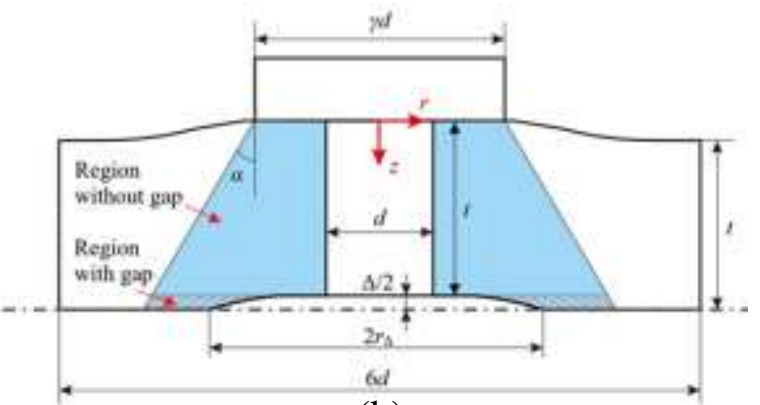

(b)

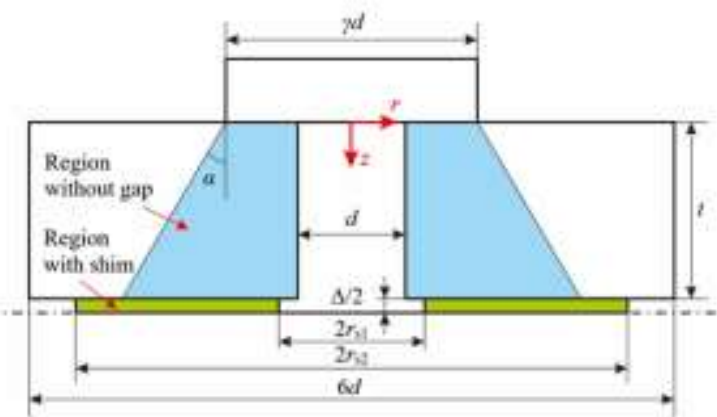

(d)

Fig. 4. Supposed transverse shear stress envelope for single-bolt single-lap composite joints: (a) without assembly gap; (b) with assembly gap; (c) with shim 'situation (a)'; (d) with shim 'situation (b)' [21]. 
In fact, actual assembly gap shape was irregular so that the effective-to-equivalent gap area method was proposed to convert the arbitrary gap shape to equivalent circular ring gap shape. The central idea is to calculate the effective gap area inside the highly stressed portion for arbitrary gap, then convert it to the equivalent gap area of circular ring shape, which is concentric with the hole. Taking the rectangle gap shape in Fig. 5 as an example (the assembly gap distributes at the right side of the vertical thick line, whose gap length is $L_{\Delta}$ and gap width is $b_{\Delta}$ ), the blue region means the highly stressed portion, the yellow region marked as $S_{\text {eff }}$ inside the real gap represents the effective gap area, while the white region inside the real gap is the ineffective gap area. And the equivalent gap area inside the dotted line is marked as $S_{\text {equ }}$. The equivalent gap radius $\hat{r}_{\Delta}$ can be obtained by solving the Eqs. (23) (27), where $r_{\text {bd }}$ represents the radius of the highly stressed portion at location $z=t_{i}+\Delta / 2, \theta$ means the central angle of the blue sector, $\hat{r}_{\Delta}$ is the equivalent gap radius.

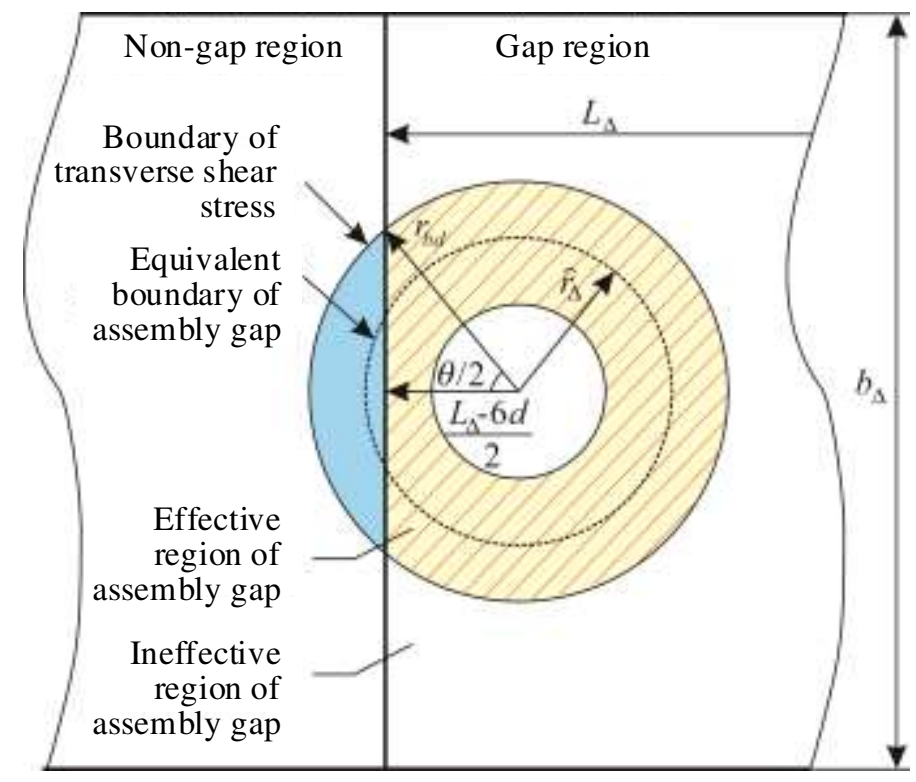

Fig. 5. Rectangle assembly gap and its equivalent assembly gap shape.

$$
S_{\text {eff }}=\pi\left(r_{\text {bd }}\right)^{2}-\left[\frac{\theta}{2}\left(r_{\text {bd }}\right)^{2}-\left(\frac{L_{\Delta}-6 d}{2}\right)^{2} \tan \frac{\theta}{2}\right](\theta \neq \pi)
$$




$$
\begin{gathered}
r_{\text {bd }}=\frac{\gamma d}{2}+\left(t_{i}+\frac{\Delta}{2}\right) \tan \alpha(i=1,2) \\
\theta=2 \arccos \left(\frac{L_{\Delta}-6 d}{2 r_{\text {bd }}}\right)\left(L_{\Delta} \neq 6 d\right) \\
S_{\text {equ }}=\pi\left(\hat{r}_{\Delta}\right)^{2} \\
S_{\text {eff }}=S_{\text {equ }}
\end{gathered}
$$

\subsection{Bolt stiffness of the load take-up region}

At the second linear region in load-displacement curve (load take-up region), the stiffness matrix $\mathbf{K}$ and displacement vector $\mathbf{x}$ of the linear equation can be also expressed by Eq. (4) and Eq. (5) [18, 19] with replacing all elements of the matrix $k_{\text {shearj }}$ to $k_{\text {boltj }}(j=1,2, \ldots, n)$. And load vector $\mathbf{F}$ at the load take-up region was given as Eq. (28) $c_{j}(j=1,2, \ldots, n)$ is the clearance between the bolt shank and the hole; $u_{\mathrm{f} j}(j=1,2, \ldots, n)$ is the maximum displacement reached at the friction region. As Eq. (29) shows, each of the bolt stiffness $k_{\text {boltj }}(j=1,2, \ldots, n)$ consists of the bolt shear stiffness item $k_{\text {shear-b }}$, bolt bending stiffness item $k_{\text {bend-b }}$, laminate bearing stiffness items $k_{\text {bear-1 }}$ and $k_{\text {bear-2 }}$, and secondary bending stiffness items $k_{\text {sec-1 }}$ and $k_{\text {sec-2 }}$, which can be calculated by Eqs. (30) (33) [21]. Where $G_{\mathrm{b}}$ is the shear modulus of the bolt, $A_{\mathrm{b}}$ is the transverse section area of the bolt, $E_{\mathrm{L} i}$ and $E_{\mathrm{T} i}$ are the equivalent elastic moduli in the longitudinal direction and in the transverse direction according to laminate theory, $t_{\mathrm{m}}$ is the load path eccentricity as the distance between the mid-plane of the laminates, $L_{\mathrm{efc} i}$ is the distance between the hole surface and the plate free end where load is applied, $E_{\mathrm{Fc} i}$ is the flexural modulus of the laminate [24], which can be obtained by flexural experiments [25], and $I_{c i}$ is the moment of inertia of the laminate. 


$$
\begin{aligned}
& \mathbf{F}=\left[\begin{array}{c}
-k_{\mathrm{bolt1}}\left(c_{1}+u_{\mathrm{f} 1}\right)+F_{\mathrm{f} 1} \\
k_{\mathrm{bolt1}}\left(c_{1}+u_{\mathrm{f} 1}\right)-F_{\mathrm{f} 1} \\
\cdots \\
-k_{\mathrm{boltj}}\left(c_{j}+u_{\mathrm{f} j}\right)+F_{\mathrm{f} j} \\
k_{\mathrm{boltj}}\left(c_{j}+u_{\mathrm{f} j}\right)-F_{\mathrm{f} j} \\
\cdots \\
-k_{\mathrm{boltn} n}\left(c_{n}+u_{\mathrm{f} n}\right)+F_{\mathrm{f} n} \\
k_{\mathrm{boltn} n}\left(c_{n}+u_{\mathrm{f} n}\right)-F_{\mathrm{f} n} \\
F_{(2 n+1)}
\end{array}\right] \\
& \frac{1}{k_{\text {bolt } j}}=\frac{1}{k_{\text {shear-b }}}+\frac{1}{k_{\text {bend-b }}}+\frac{1}{k_{\text {bear-1 }}}+\frac{1}{k_{\text {bear-2 }}}+\frac{1}{k_{\text {sec-1 }}}+\frac{1}{k_{\text {sec-2 }}}(j=1,2, \ldots, n) \\
& k_{\text {shear-b }}=\frac{3 G_{\mathrm{b}} A_{\mathrm{b}}}{2\left(t_{1}+t_{2}\right)} \\
& k_{\text {bend-b }}=\frac{E_{\mathrm{b}} t_{1} t_{2}}{2\left(t_{1}+t_{2}\right)} \\
& k_{\mathrm{bear}-i}=t_{i} \sqrt{E_{\mathrm{L} i} E_{\mathrm{T} i}}(i=1,2) \\
& k_{\mathrm{sec}-i}=\frac{2}{t_{\mathrm{m}} t_{i}} \cdot \frac{L_{\mathrm{efc} 2}^{4} E_{\mathrm{Fcl} 1}^{2} I_{\mathrm{c} 1}^{2}+2 L_{\mathrm{efc} 1} L_{\mathrm{efc} 2} E_{\mathrm{Fc} 1} E_{\mathrm{Fc} 2} I_{\mathrm{cl}} I_{\mathrm{c} 2}\left(2 L_{\mathrm{efc} 1}^{2}+3 L_{\mathrm{efc} 1} L_{\mathrm{efc} 2}+2 L_{\mathrm{efc} 2}^{2}\right)+L_{\mathrm{efc} 1}^{4} E_{\mathrm{Fc} 2}^{2} I_{\mathrm{c} 2}^{2}}{L_{\mathrm{efc} 1} L_{\mathrm{efc} 2}\left(L_{\mathrm{efc} 2}^{3} E_{\mathrm{Fc} 1} I_{\mathrm{c} 1}+L_{\mathrm{efc} 1}^{3} E_{\mathrm{Fc} 2} I_{\mathrm{c} 2}\right)}(i=1,2)
\end{aligned}
$$

\section{Model validation}

\subsection{Experiment}

In order to validate the proposed analytical model, a typical single-shear experiment for three-bolt composite joints according to the ASTM D5961 was conducted. The three-bolt joints specimens were prepared with a 3-axis numerical control machine. As shown in Fig. 6, after drilling, holes of the specimens were observed by the digital microscope VHX-600E (KEYENCE, Japan) with 20X lens and there were no visible damages around the holes; diameter of three holes were measured by the coordinate measuring machine, and average diameter values of all the hole were $d=6.1 \mathrm{~mm}$. According to the ASTM D5961, length of the laminate was $L=184.2 \mathrm{~mm}$ (Length of the clamp region was set as $50 \mathrm{~mm}$ ), width of the 
laminate was $W=36.6 \mathrm{~mm}$ (Fig. 7). The mechanical properties of composite laminates IMS194/977-2 are given in Table 1, in which $E_{\mathrm{Fc}}$ represents the flexural modulus of the laminate [21]. The equivalent engineering constants of the laminate were obtained by the homogenization method reported by Mandal et al. [26]. The specimen has a symmetric lay-up [45/90/-45/0/90/0/-45/90/45/-45] , which yielded a laminate thickness of $3.76 \mathrm{~mm}$ (single layer thickness was $0.188 \mathrm{~mm}$ ).

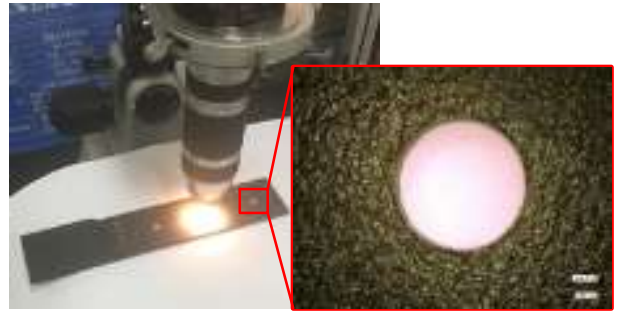

(a) Damage observation

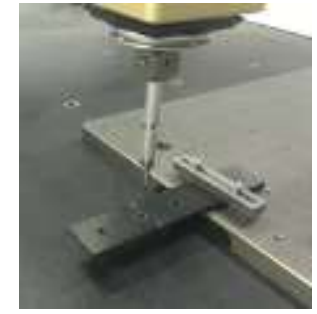

(b) Hole diameter measurement

Fig. 6. Damage observation and hole diameter measurement.

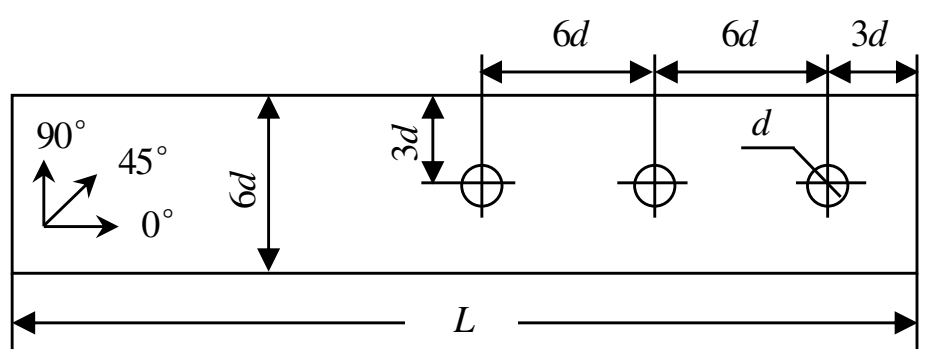

Fig. 7. Size of the single-lap three-bolt composite joints [22].

Table 1 The mechanical properties of the IMS194/977-2 and its equivalent engineering constants [21].

\begin{tabular}{|c|c|c|c|c|c|c|c|}
\hline \multicolumn{8}{|c|}{ Mechanical properties } \\
\hline $\begin{array}{c}E_{1} \\
/ \mathrm{GPa}\end{array}$ & $\begin{array}{c}E_{2}\left(E_{3}\right) \\
/ \mathrm{GPa}\end{array}$ & $\begin{array}{c}G_{12}\left(G_{13}\right) \\
/ \mathrm{GPa}\end{array}$ & $\begin{array}{c}G_{23} \\
/ \mathrm{GPa}\end{array}$ & $v_{12}\left(v_{13}\right)$ & $v_{23}$ & $\begin{array}{l}E_{\mathrm{Fc}} \\
/ \mathrm{GPa}\end{array}$ & \\
\hline 165 & $8.17^{*}$ & 4.27 & $2.75^{*}$ & 0.33 & $0.48^{*}$ & 31.26 & \\
\hline \multicolumn{8}{|c|}{ Equivalent engineering constants } \\
\hline $\begin{array}{c}E_{\mathrm{L}} \\
/ \mathrm{GPa}\end{array}$ & $\begin{array}{c}E_{\mathrm{T}} \\
/ \mathrm{GPa}\end{array}$ & $\begin{array}{c}G_{\mathrm{xy}} \\
/ \mathrm{GPa}\end{array}$ & $\begin{array}{c}G_{\mathrm{xz}} \\
/ \mathrm{GPa}\end{array}$ & $\begin{array}{c}G_{\mathrm{yz}} \\
/ \mathrm{GPa}\end{array}$ & $v_{\mathrm{xy}}$ & $v_{\mathrm{xy}}$ & $v_{\mathrm{yz}}$ \\
\hline 52.13 & 71.92 & 22.65 & 3.44 & 3.59 & 0.26 & 0.36 & 0.31 \\
\hline
\end{tabular}

* The value is set according to the transversely isotropic assumption and engineering experience.

All the fasteners were made of SCM435 alloy steel $\left(E_{\mathrm{b}}=162.43 \mathrm{GPa}, v_{\mathrm{b}}=0.286\right.$ [27]) with real bolt 
diameter of $5.97 \mathrm{~mm}$ so that bolt-hole clearances were all $0.13 \mathrm{~mm}$. The fasteners were preloaded by SK25 torque wrench (Xite, Chinese Taiwan) with tightening torque of $7.7 \mathrm{~N} \cdot \mathrm{m}$. The experiment was conducted on the WDW-100 electronic universal testing machine (Kexin, China) with displacement loading speed of $1.0 \mathrm{~mm} / \mathrm{min}$. The displacement of the specimen was recorded by $\mathrm{Y} 50 / 25-\mathrm{N}$ extensometer (Sanjing, China, measuring range $25.0 \mathrm{~mm}$, accuracy 0.5 ), and the load was recorded by the testing machine. Four specimens in total were tested, experiment set-up and load-displacement curves were shown in Fig. 8. For the highly torqued single-lap multi-bolt joints, typical load-displacement curve contains three regions before damage occurs, which are friction region, transition region and load take-up region. The friction region is mainly produced by friction force between the laminates, whose stiffness is named as shear stiffness $k_{\text {shear }}$. The transition region, where displacement arises without any increase in load, is determined by the bolt-hole clearances [4]. After the transition region, it comes to the load takeup region, the bolt shank begins to contact the laminates and load begin arise as the displacement increases, whose stiffness is named as bolt stiffness $k_{\text {bolt }}$.

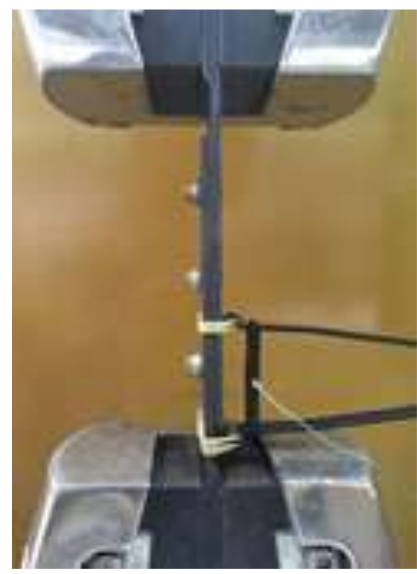

(a)

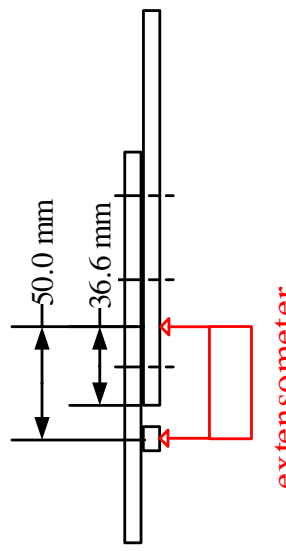

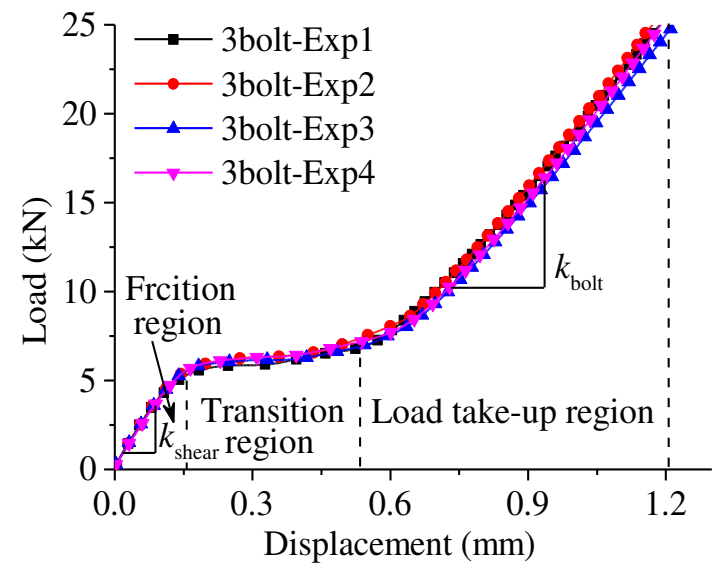

(b)

Fig. 8. Experiment set-up and typical load-displacement response for single-lap three-bolt composite joints: (a) experiment set-up; (b) load-displacement curves.

\subsection{Finite element method}

Considering the complexity of experimental conditions for multi-bolt composite joints with assembly 
gap and/or shim, finite element analysis was conducted and compared with the spring-mass model, as shown in Fig. 9. The laminate in Abaqus was modelled without the clamped region so that the length of the laminate was $4 d+3 \times 6 d=134.2 \mathrm{~mm}$. Other parameters were same with the experiment.

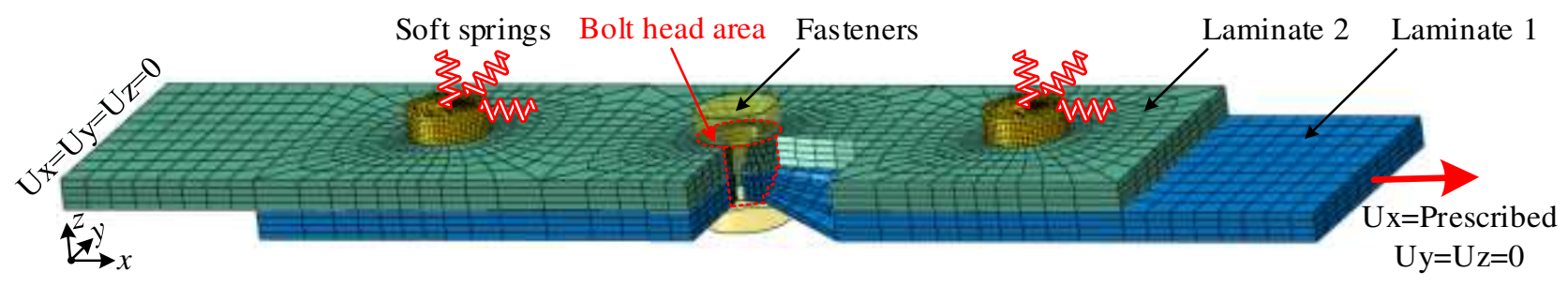

Fig. 9. Finite element model of three-bolt composite joints.

C3D8R elements (in Abaqus) of enhanced hourglass control method were used for both laminates and fasteners. After mesh dependence studying, considering the computational cost and results accuracy, in-plane mesh size within the bolt head area was set as $0.5 \mathrm{~mm}$, that of other areas was $3.0 \mathrm{~mm}$, and four elements were set through the thickness for each laminate. The fasteners were all modelled as one-piece parts, which have the global element size of $0.5 \mathrm{~mm}$. The laminates were assigned with homogenous mechanical properties as given in Table 1. Finite sliding and surface-to-surface discretization methods were used for interactions. The friction coefficients between the laminates were 0.42 , while that between the hole walls and bolt shanks were set as 0.1 , referring to the literature [28]. The friction coefficient between the laminate and bolt head has an influence on the transition region. Only when it is small enough, the slope of the load-displacement curve in the transition region can be regarded as zero. In this paper, the friction coefficients between the laminates and bolt heads were set as 0.01 . In addition, soft springs with stiffness of $1 \mathrm{~N} / \mathrm{mm}$ were added to limit all the displacement degrees of freedom of the fasteners, which can help improve convergence.

Two steps were set in Abaqus: (1) in the first step, the bolt loads of $5 \mathrm{kN}$ (corresponding tightening torque of $7.7 \mathrm{~N} \cdot \mathrm{m})$ were added to all fasteners, and displacement degrees of freedom $(\mathrm{Ux}, \mathrm{Uy}, \mathrm{Uz})$ were limited for the two laminates; (2) in the second step, 'fix at current length' method (a load method in 
Abaqus) was used for the bolt loads, and displacement load in the $x$ direction was applied to the reference point, which is constrained with the free side nodes of the upper laminate with kinematic coupling.

\section{Results and discussion}

Firstly, experimental results were used to validate the assumption of conical and spherical stress envelope in analytical model. The surface profiles of the three-bolt joints specimen after experiment was obtained by the digital microscope KEYENCE VHX-600E, as shown in Fig. 10. The worn areas at the outer surface (close to the bolt head) and at the contact surface (between two laminates) were marked with red circles, whose maximum diameters were measured. It can be seen that the worn areas caused by friction at the outer surface are smaller than that at the contact surface around all three holes, which indicates that the assumption of conical and spherical stress envelope in Fig. 3 is reasonable. In addition, diameter of the worn area around the hole 3 is greater than that around the hole 2 , and that around the hole 1 is the smallest. Hole 3 is closest to the mobile loading end, while hole 1 is the farthest from the mobile loading end. The difference in severity of wear for three holes means that friction sliding contact times in transition region are different, which indicates that the local materials around three holes sequentially go into the transition region and bolt-hole clearances of three holes are eliminated gradually. 


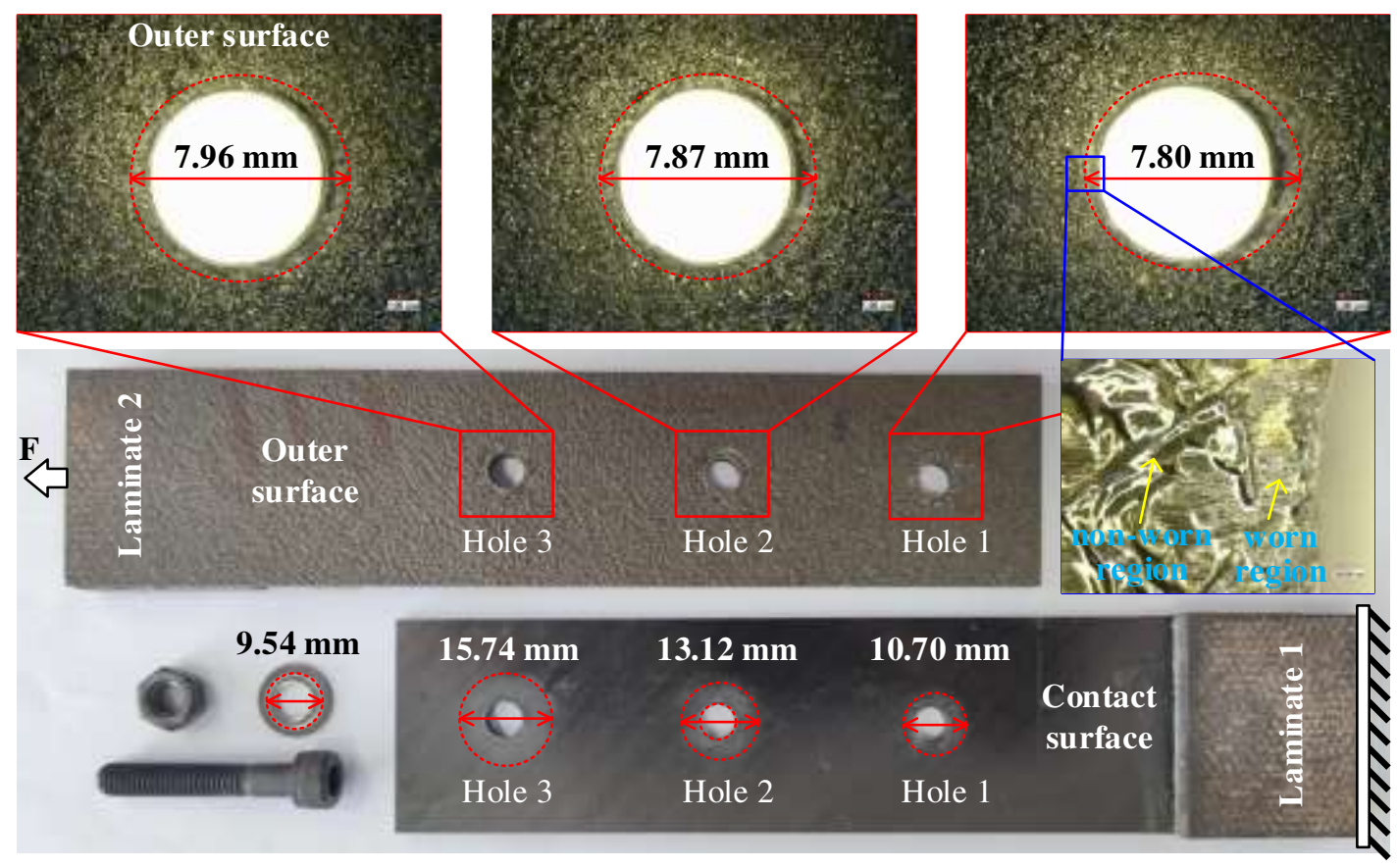

Fig. 10. Surface profiles of the single-lap three-bolt composite joints after experiment.

Secondly, single-shear experiment was conducted, as shown in Fig. 11, and the strains along the loading direction around three holes were measured by strain gauge (sensitivity coefficient $2.0 \pm 1 \%$, resistance $120 \pm 1 \Omega$ ) and DH3816N strain measuring instrument (Donghua, China) in order to validate the gradual elimination of bolt-hole clearances for three-bolt composite joints. The strain gauges were attached to the laminate 2 , which was clamped to the moving end of the testing machine. The distances between the center of the strain gauge and the center of the hole were all $11.85 \mathrm{~mm}$ for three holes. In Fig. 11, strain value near hole 3 is larger than that of hole 2, and strain value near hole 2 is larger than that of hole 1. Meanwhile, it can be obviously seen that strain-time curves of hole 2 and hole 3 have gone out of the transition region, while that of hole 1 is still in the transition region, which means bolt-hole clearances of hole 1 is still not eliminated. It validates the assumption that the local materials around three holes sequentially go into the transition region and bolt-hole clearances of three holes are eliminated gradually. 

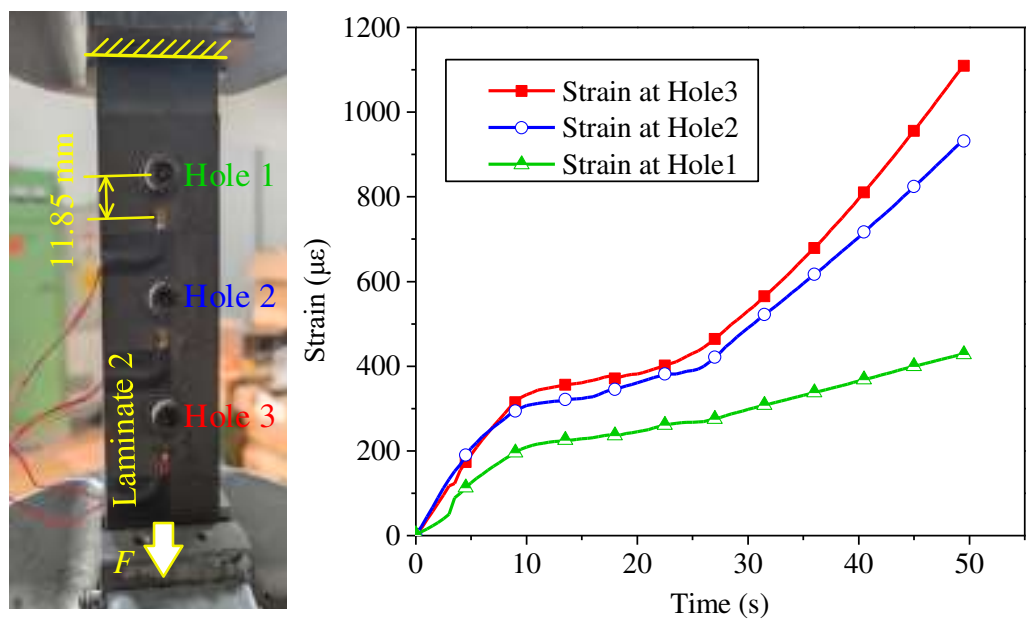

Fig. 11. Experimental set-up and strain-time curves of the single-lap three-bolt composite joints.

Then load-displacement curves from experiments (Exp), analytical model (AM) and finite element models (FEM) for single-lap three-bolt joints without assembly gap were compared as shown in Fig. 12. It can be seen that load-displacement curves of the joints before damage occurs can be divided into 3 regions: friction region, transition region and load take-up region. The curve tendency of the AM agrees better with the experiments than that of the FEM, especially in the transition region. The maximum static friction of the experiments is $6173 \pm 190 \mathrm{~N}$, while that of the analytical model and finite element model are $6300 \mathrm{~N}$ and $6177 \mathrm{~N}$, respectively; the relative error between the analytical model and experiment is $2.1 \%$, and that between finite element model and experiment is $-2.4 \%$. Average transition region length of the experiments is $0.48 \mathrm{~mm}$, that of the AM and the FEM are $0.39 \mathrm{~mm}$ and $0.15 \mathrm{~mm}$, respectively. It is because the AM considers the gradual elimination of the bolt-hole clearances for three bolts, while the FEM supposes that bolt-hole clearances for three bolts were eliminated at the same time. Meanwhile, slight increase in load in the transition region indicates that during the sliding process of laminate 2 and laminate 1, some bolts have contacted with the holes while others have not. 


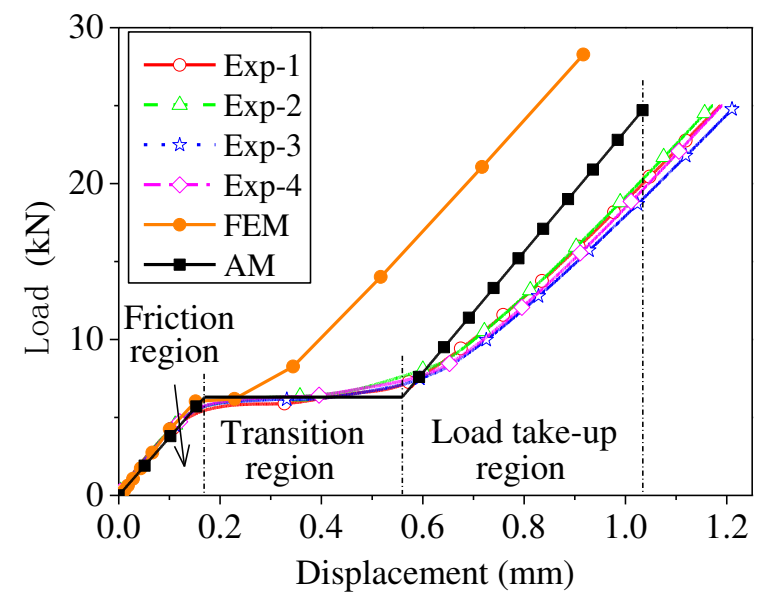

Fig. 12. Model validation with experiments and FEM of the three-bolt joints without assembly gap.

The shear stiffness and bolt stiffness of the joints from the experiments, FEM and analytical models were shown in Fig. 13. The shear stiffness from experiments is $37095 \pm 124 \mathrm{~N} / \mathrm{mm}$ for multi-bolt joints without assembly gap, while that from analytical model and finite element model are $37209 \mathrm{~N} / \mathrm{mm}$ and $44065 \mathrm{~N} / \mathrm{mm}$, respectively; the relative error between the analytical model and experiment is $0.3 \%$, and that between finite element model and experiment is $18.8 \%$. The bolt stiffness from experiments is $32368 \pm 770 \mathrm{~N} / \mathrm{mm}$ for multi-bolt joints without assembly gap, while that from analytical model and finite element model are $38787 \mathrm{~N} / \mathrm{mm}$ and $36367 \mathrm{~N} / \mathrm{mm}$, respectively; the relative error between the analytical model and experiment is $19.8 \%$, and that between finite element model and experiment is $12.4 \%$. As abovementioned, both shear stiffness and bolt stiffness of the analytical model agree well with experiments so that the spring-mass model of single-lap multi-bolt composite joints was validated. Meanwhile, the relative errors of stiffness between the FEM and experiments are all in an acceptable range, which indicates that the abovementioned finite element method can be used as a validation method of the shear stiffness and the bolt stiffness. 


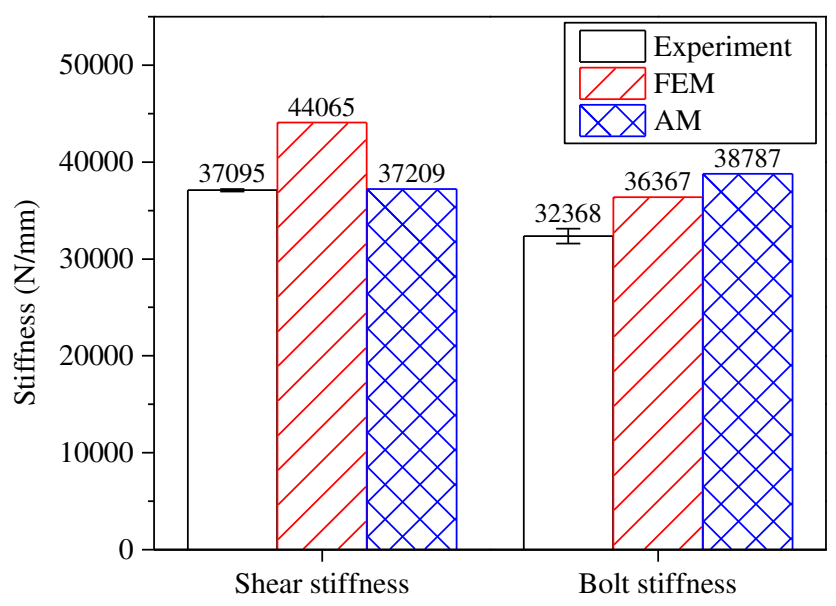

Fig. 13. Shear stiffness comparison and bolt stiffness comparison among the experiments, FEM and analytical models.

Finally, the finite element method that has been validated above was used to validate the analytically predicted results of other situations with different assembly gaps and/or shims, named as 'Gap A', 'Gap B', 'Shim A' and 'Shim B'.

'Gap A' situation with three individual assembly gap regions was illustrated in Fig. 14(a), for which the shear stiffness of the laminates calculating uses Eqs. (13) (15). The assembly gap sizes for all three bolts of the 'Gap A' situation are $1.0 \mathrm{~mm}$, and gap radii are all $6.0 \mathrm{~mm}$. Whilst 'Gap B' situation with a rectangle assembly gap region across the bolt 1 and bolt 2 (gap length was $36.6 \mathrm{~mm}$, gap width was 36.6 $\mathrm{mm}$, assembly gap size was $1.0 \mathrm{~mm}$ ) was illustrated in Fig. 14(b), for which the effective-to-equivalent gap area method must be used to convert the real gap shape to equivalent circular ring gap shape and then using Eqs. (13) (15) to calculate the shear stiffness of the laminates. The equivalent gap radii for bolt 1 , bolt 2 and bolt 3 of the 'Gap B' situation were $4.8 \mathrm{~mm}, 4.8 \mathrm{~mm}$ and $0 \mathrm{~mm}$, respectively.

'Shim A' situation is the shimming situation of the 'Gap A' situation, which has three individual assembly gap regions with assembly gap size of $1.0 \mathrm{~mm}$, as shown in Fig. 14(c), while 'Shim B' situation compensates the assembly gap region that distributes across all three bolts (assembly gap size was 1.0 $\mathrm{mm}$ ), as shown in Fig. 14(d). The equivalent gap radii for all three bolts of the 'Shim B' situation were 
$25.9 \mathrm{~mm}\left(\hat{r}_{\Delta}>3 \sqrt{2} d \approx 25.9 \mathrm{~mm}\right)$. The shimming materials used for both 'Shim A' and 'Shim B' were Hysol EA 9394 epoxy paste adhesive (Henkel Inc., USA), whose elastic modulus was $4237 \mathrm{MPa}$ and Poisson's ratio was 0.37 [29].

(a)

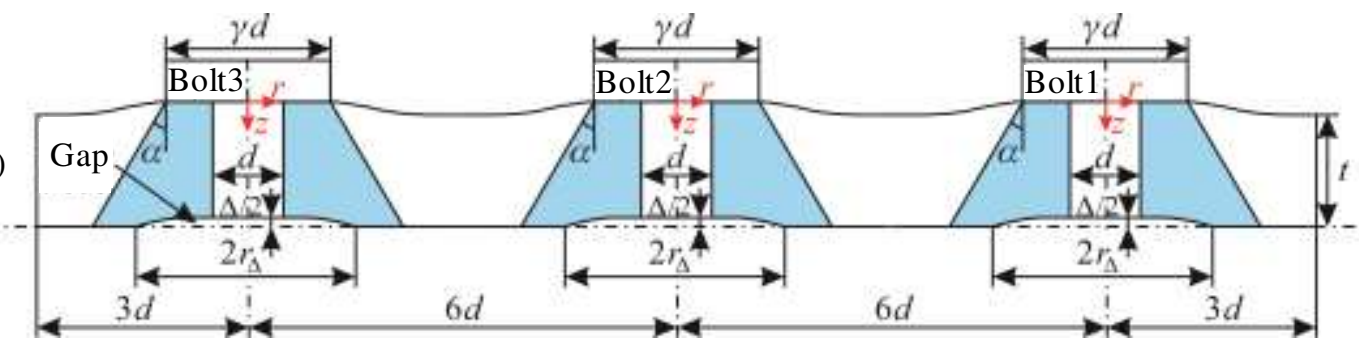

(b)

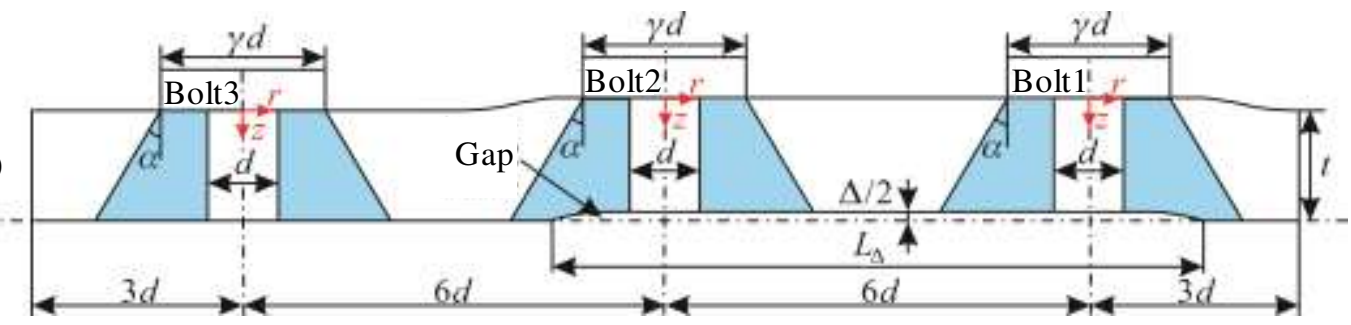

(c)

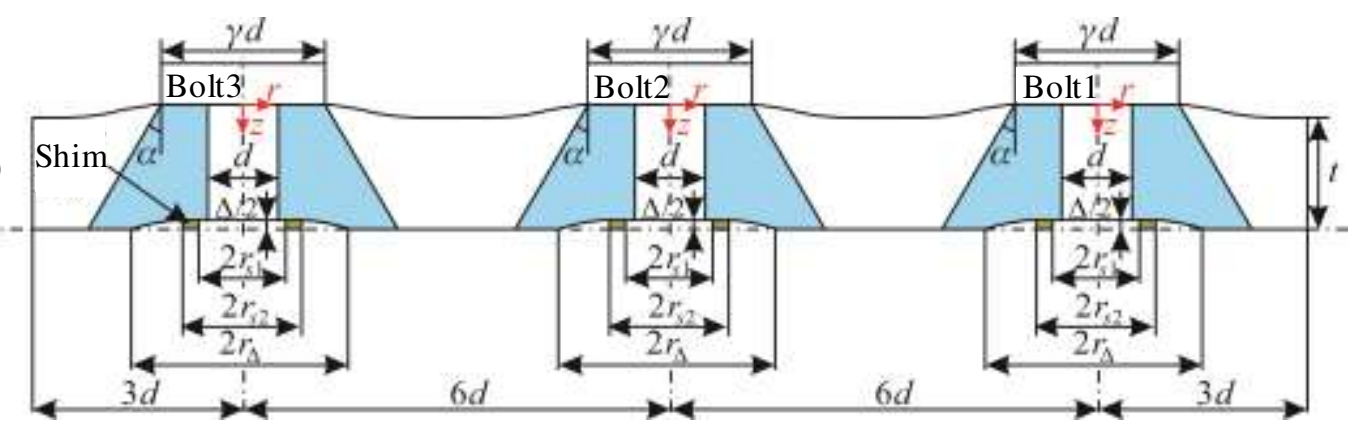

(d)

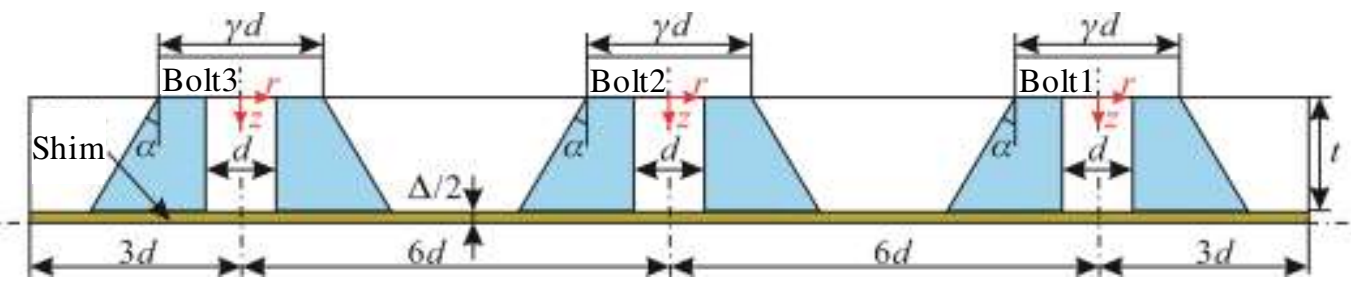

Fig. 14. Four interested situations with different assembly gap and/or shims: (a) 'Gap A'; (b) 'Gap B';

(c) 'Shim A'; (d) 'Shim B'.

The shear stiffness and bolt stiffness results from the FEM and AM for four interested situations abovementioned were shown in Fig. 15. The maximum relative error of the shear stiffness between the $\mathrm{AM}$ and the FEM is $17.0 \%$, while that of the bolt stiffness is $15.8 \%$, which indicates that the proposed 
analytical model was effective to predict the stiffness of the single-lap multi-bolt composite joints subjected to single-shear loading.

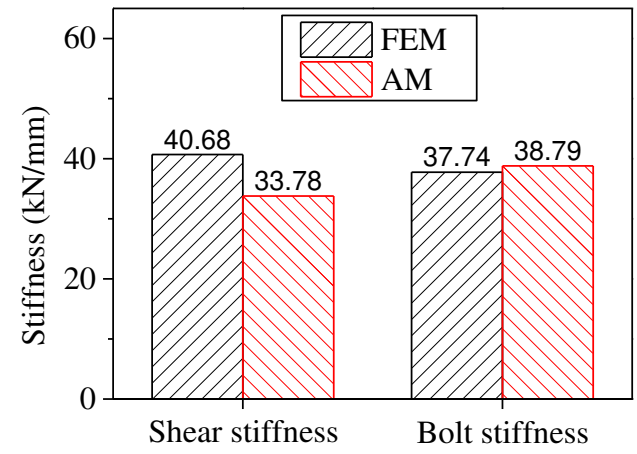

(a)

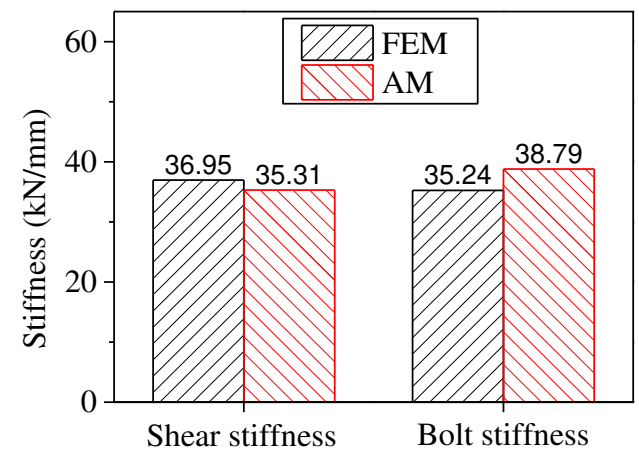

(c)

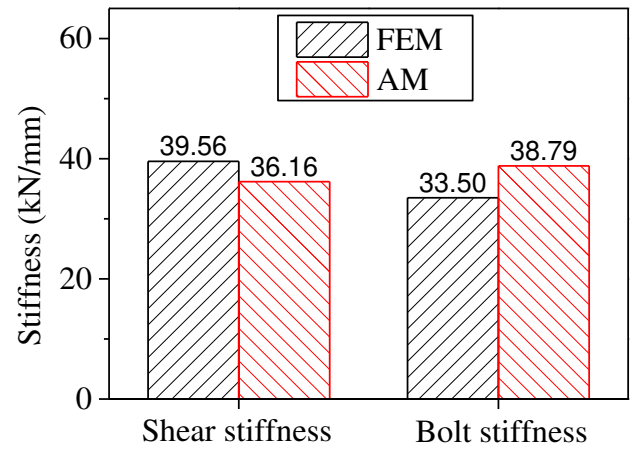

(b)

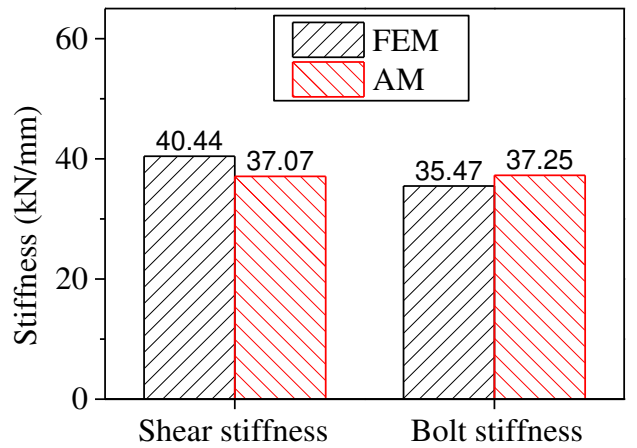

(d)

Fig. 15. Shear stiffness and bolt stiffness results from the FEM and AM for four interested situations: (a)

'Gap A’; (b) 'Gap B’; (c) ‘Shim A’; (d) ‘Shim B'.

\section{Conclusion}

In this paper, a spring-mass stiffness model for single-lap multi-bolt composite joints considering assembly gap and gap shimming was proposed to predict the joint stiffness, including shear stiffness and bolt stiffness. The multi-bolt joints were converted into individually single-bolt joint based on the assumption that there are no overlap regions between the highly stressed portions for adjacent holes. And effective-to-equivalent gap area method was proposed to convert the arbitrary assembly gap shape to the basic circular shape. The proposed model considered the conical and spherical envelope of the transverse shear stress, which was validated by worn area difference of the outer surface and the contact surface of the laminates. Meanwhile, it took into account the gradual elimination of the bolt-hole clearances by using 
the sum of all bolt-hole clearances as length of the transition region, which was validated by the straintime responses in experiments. To validate the proposed model for multi-bolt composite joints, typical single-lap three-bolt composite joints experiments were conducted and finite element model was established. The maximum relative error of joint stiffness between the analytical model and experiment of $19.8 \%$, while that between the finite element model and the experiment was $12.4 \%$. The finite element method that has been validated by the experiments was used as an assistant validation of predicted values of shear stiffness and bolt stiffness. The maximum relative error of the shear stiffness between the analytical model and the finite element model is $17.0 \%$, while that of the bolt stiffness is $15.8 \%$, which indicates that the proposed analytical model was effective to predict the stiffness of the single-lap multibolt composite joints subjected to single-shear loading.

\section{Availability of Data and Materials}

The datasets used and/or analysed during the current study are available from the corresponding author on reasonable request.

\section{Competing Interests}

The authors declare that they have no competing interests.

\section{Funding}

This work was supported by the National Natural Science Foundation of China [Grant No. 51875079], China Postdoctoral Science Foundation [Grant No. 2020M680937 \& No. 2020M670734], National Key Research and Development Project [Grant No.2020YFB2009805], LiaoNing Revitalization Talents Program [Grant No. XLYC1907196] and National Defense Basic Scientific Research program of China [Grant No. 2019-JCJQ-JJ-547]. The authors would like to acknowledge the above financial support.

\section{Authors' Contributions}

YY proposed the analytical model and wrote the article. BY proposed the idea of experiments. WJ assisted to conduct the simulations. DF helped in analysing the data. 


\section{Acknowledgements}

The authors would like to acknowledge the abovementioned financial support.

\section{References}

[1] Saadat M and Cretin C. Dimensional variations during Airbus wing assembly. Assembly Automation 2002;22(3):270-276.

[2] Baran I, Cinar K, Ersoy N, Akkerman R and Hattel JH. A review on the mechanical modeling of composite manufacturing processes. Archives of Computational Methods in Engineering 2017;24:365-395.

[3] Yuan Z, Wang Y, Peng X, Wang J and Wei S. An analytical model on through-thickness stresses and warpage of composite laminates due to tool-part interaction. Composites Part B: Engineering 2016;91:408-413.

[4] Hassan MH, Othman AR and Kamaruddin S. A review on the manufacturing defects of complexshaped laminate in aircraft composite structures. The International Journal of Advanced Manufacturing Technology 2017:1-14.

[5] Goering J, Bohlmann R, Wanthal S, Kautz E and Neri LM. Assembly induced delaminations in composite structures. In: Ninth DOD (NASA) FAA Conference on Fibrous Composites in Structural Design; 1992. p. 1353-1377.

[6] Campbell FC. Manufacturing processes for advanced composites. Elsevier Science; 2003.

[7] Chouvion B, Popov A, Ratchev S, Mason C and Summers M. Interface management in wing-box assembly. 2011.

[8] Hühne C, Zerbst AK, Kuhlmann G, Steenbock C and Rolfes R. Progressive damage analysis of composite bolted joints with liquid shim layers using constant and continuous degradation models. Composite Structures 2010;92(2):189-200.

[9] Liu L. The influence of the substrate's stiffness on the liquid shim effect in composite-to-titanium hybrid bolted joints. Proceedings of the Institution of Mechanical Engineers, Part G: Journal of Aerospace Engineering 2013;228(3):470-479.

[10] Liu L, Zhang J, Chen K, Wang H and Liu M. Experimental and numerical analysis of the mechanical behavior of composite-to-titanium bolted joints with liquid shim. Aerospace Science and Technology 2016;49:167-172.

[11] Comer AJ, Dhôte JX, Stanley WF and Young TM. Thermo-mechanical fatigue analysis of liquid shim in mechanically fastened hybrid joints for aerospace applications. Composite Structures 2012;94(7):2181-2187.

[12] Dhôte JX, Comer AJ, Stanley WF and Young TM. Study of the effect of liquid shim on single-lap joint using 3D digital image correlation. Composite Structures 2013;96:216-225.

[13] Dhôte JX, Comer AJ, Stanley WF and Young TM. Investigation into compressive properties of liquid shim for aerospace bolted joints. Composite Structures 2014;109:224-230.

[14] Zhai Y, Li D, Li X and Wang L. An experimental study on the effect of joining interface condition on bearing response of single-lap, countersunk composite-aluminum bolted joints. Composite Structures 2015;134:190-198.

[15] Tate MB and Rosenfeld SJ. Preliminary investigation of the loads carried by individual bolts in bolted joints. 1946.

[16] Nelson WD, Bunin BL and Hart-Smith LJ. Critical joints in large composite aircraft structure. NASA Contractor Report 3710; 1983.

[17] McCarthy MA, McCarthy CT and Padhi GS. A simple method for determining the effects of bolt- 
hole clearance on load distribution in single-column multi-bolt composite joints. Composite Structures 2006;73(1):78-87.

[18] McCarthy CT and Gray PJ. An analytical model for the prediction of load distribution in highly torqued multi-bolt composite joints. Composite Structures 2011;93(2):287-298.

[19] Olmedo A, Santiuste C and Barbero E. An analytical model for the secondary bending prediction in single-lap composite bolted-joints. Composite Structures 2014;111:354-361.

[20] Olmedo A. Development of predictive models of mechanical behaviour of composite joints (in Spanish) [Doctor's thesis]. 2015.

[21] Yang Y, Liu X, Wang Y-Q, et al. An enhanced spring-mass model for stiffness prediction in singlelap composite joints with considering assembly gap and gap shimming. Composite Structures 2018;187:18-26.

[22] ASTM D5961/D5961M. Standard test method for bearing response of polymer matrix composite laminates. American Society for Testing and Materials; 2013.

[23] Nassar SA and Abboud A. An improved stiffness model for bolted joints. Journal of Mechanical Design 2009;131(12):121001-1-11.

[24] Reddy J. Mechanics of laminated composite plates and shells: theory and analysis. CRC Press; 2004.

[25] ASTM D7264/D7264M. Standard test method for flexural properties of polymer matrix composite materials. American Society for Testing and Materials; 2015.

[26] Mandal B and Chakrabarti A. A simple homogenization scheme for 3D finite element analysis of composite bolted joints. Composite Structures 2015;120:1-9.

[27] Qiu M. Subcritical spheroidizing annealing of SCM435 cold heading steel (in Chinese) [Master's thesis]. 2014.

[28] McCarthy CT, McCarthy MA, Stanley WF and Lawlor VP. Experiences with modeling friction in composite bolted joints. Journal of Composite Materials 2005;39(21):1881-1908.

[29] Henkel Inc. Hysol EA 9394 technical data sheet. 2002. Avaiable from: $<$ https://tds.us.henkel.com/NA/UT/HNAUTTDS.nsf/web/D61948C932B43DF38525715C001BD4 00/\$File/Hysol_EA_9394-EN.pdf>. 
Figures
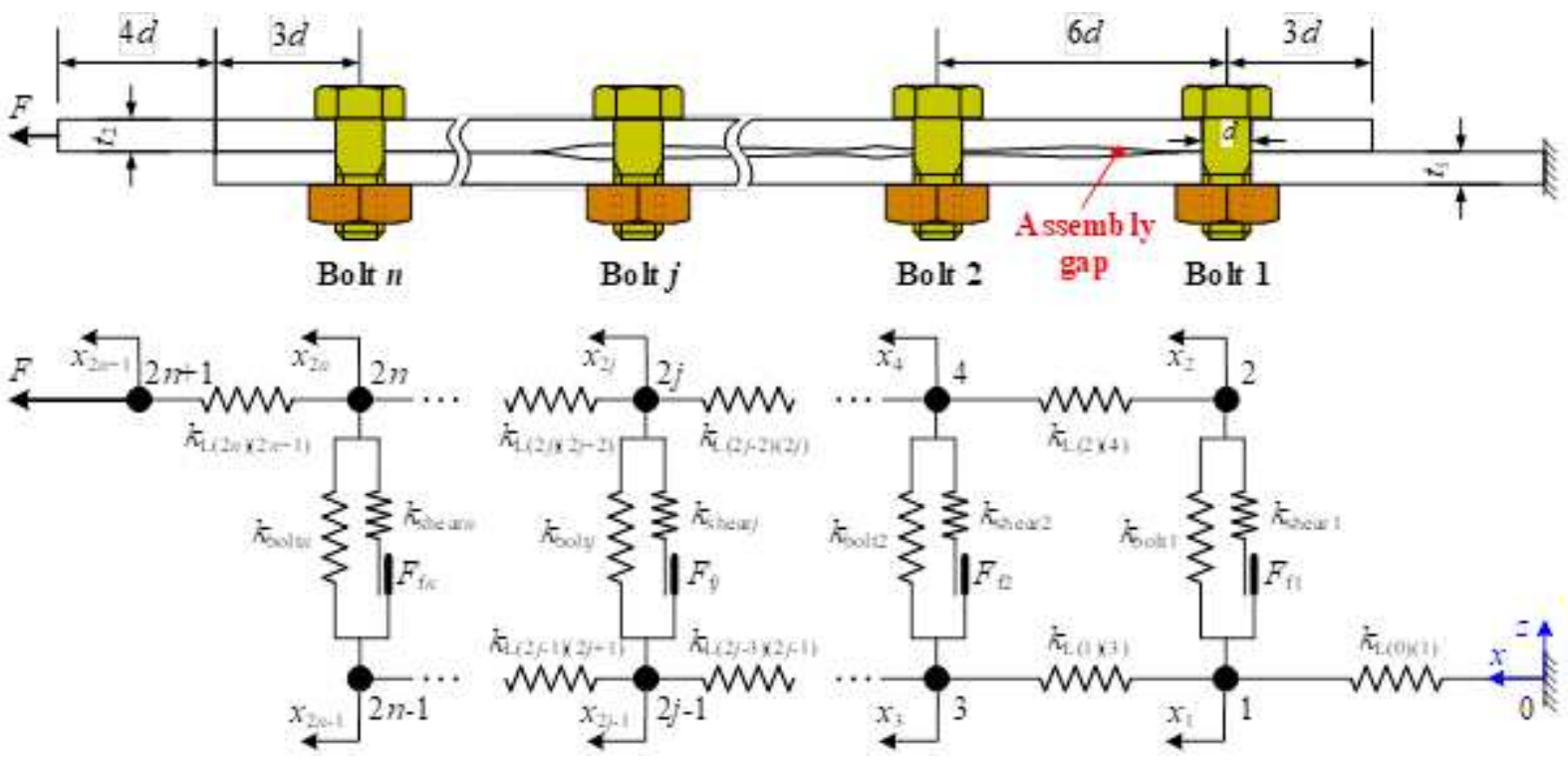

Figure 1

Multi-bolt single-lap joints with assembly gap and its spring-mass system model.

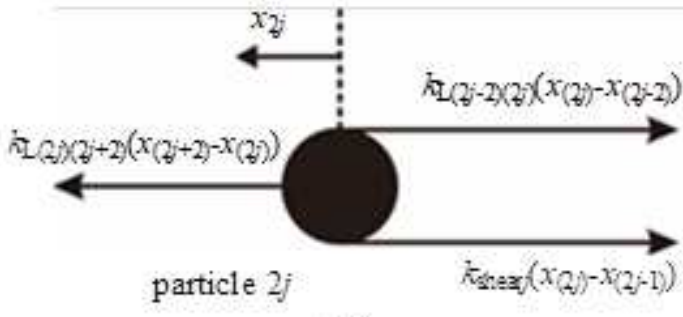

(a)

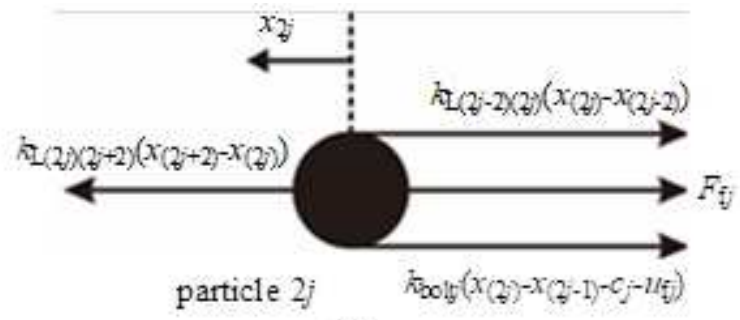

(b)

Figure 2

Free-body diagrams of particle 2j: (a) at friction region; (b) at load take-up region.

Corical and spherical envelope

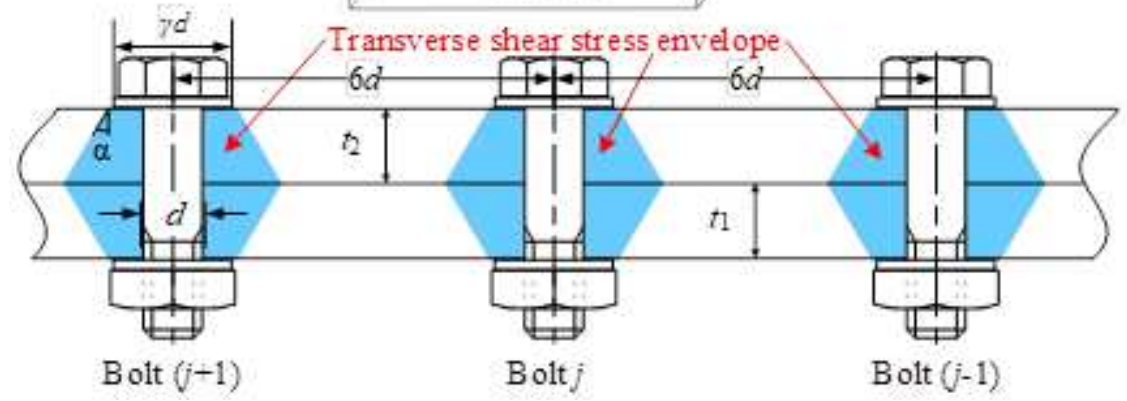

Figure 3 
Supposed transverse shear stress envelope of the multi-bolt joints.

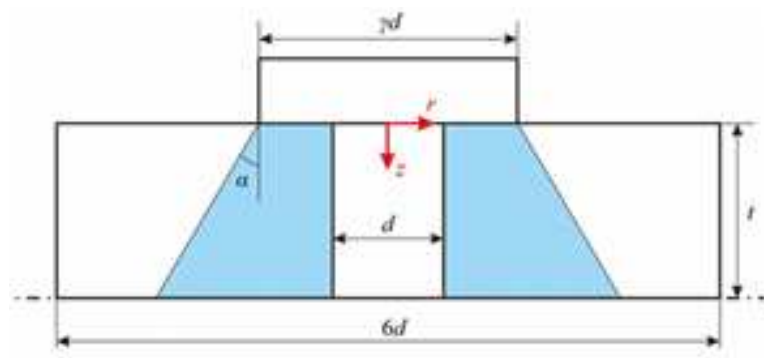

(a)

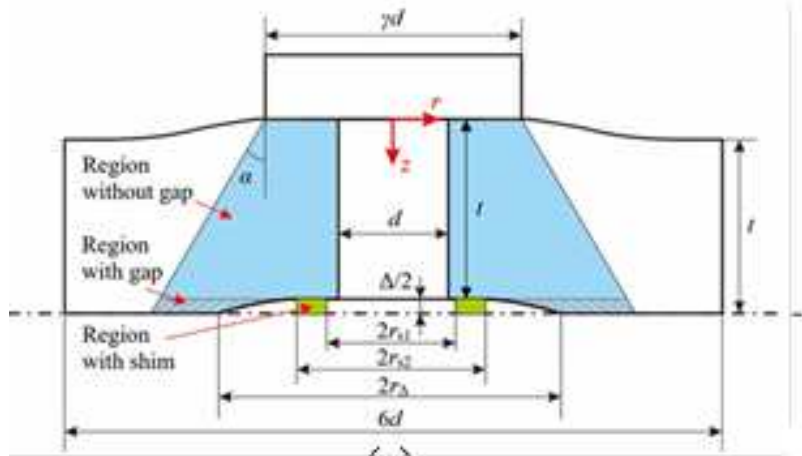

(c)

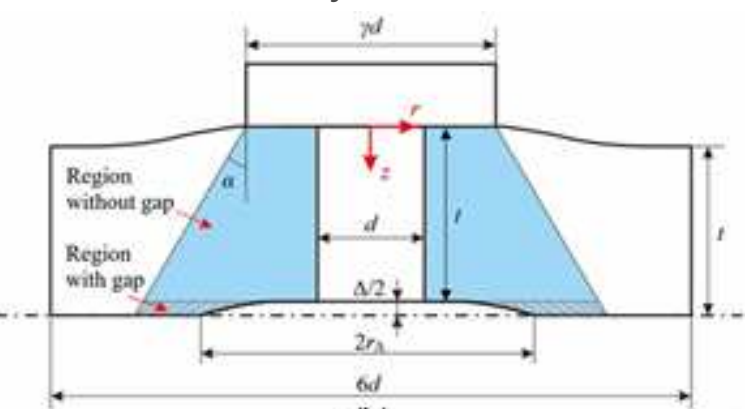

(b)

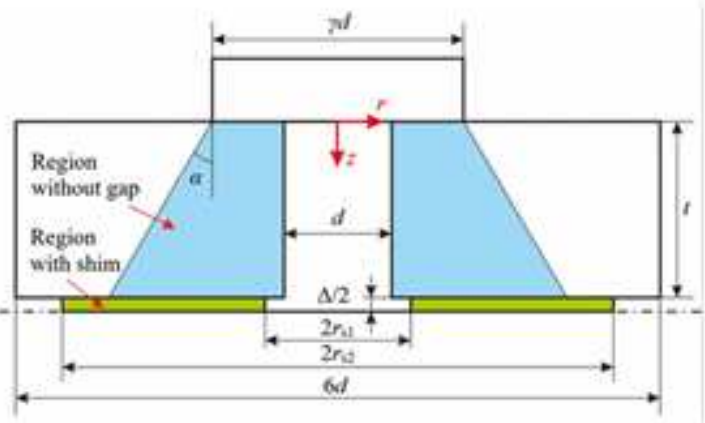

(d)

\section{Figure 4}

Supposed transverse shear stress envelope for single-bolt single-lap composite joints: (a) without assembly gap; (b) with assembly gap; (c) with shim 'situation (a)'; (d) with shim 'situation (b)' [21].

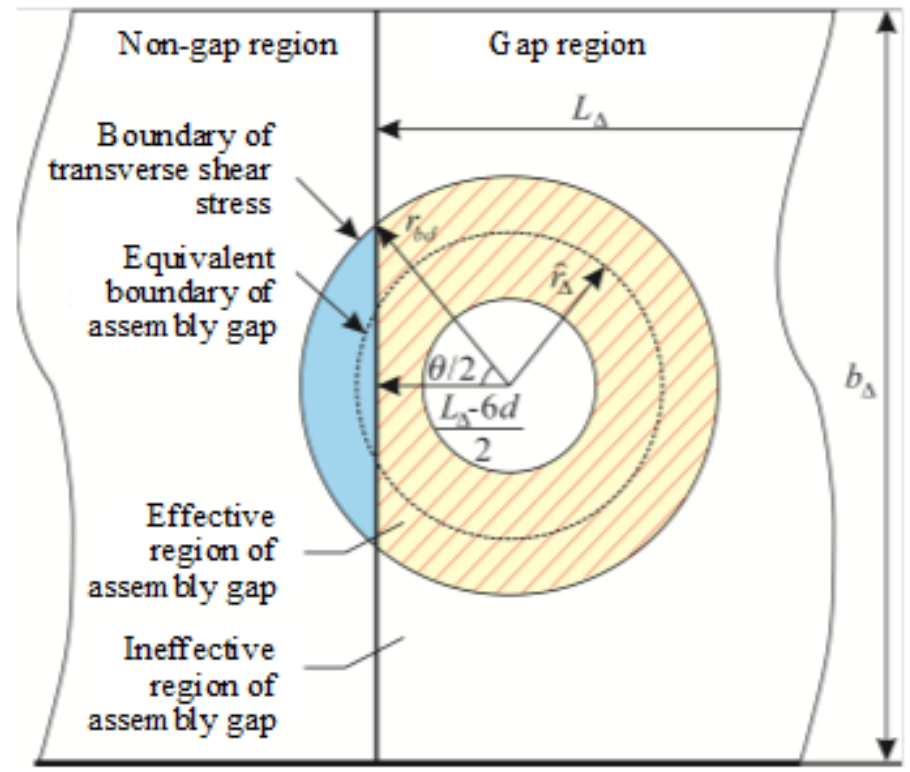

Figure 5

Rectangle assembly gap and its equivalent assembly gap shape. 


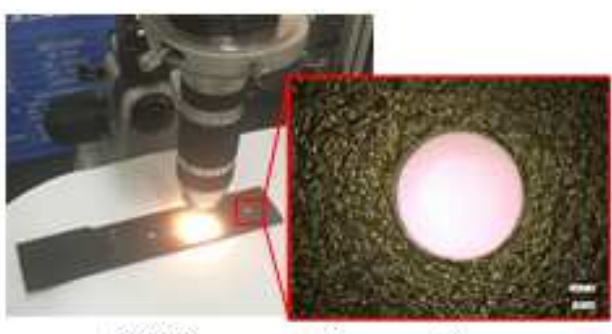

(a) Damage observation

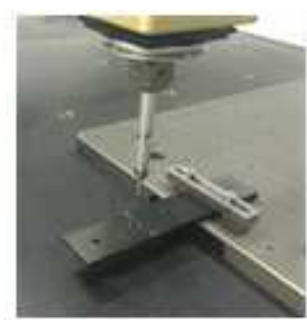

(b) Hole diameter measurement

\section{Figure 6}

Damage observation and hole diameter measurement.

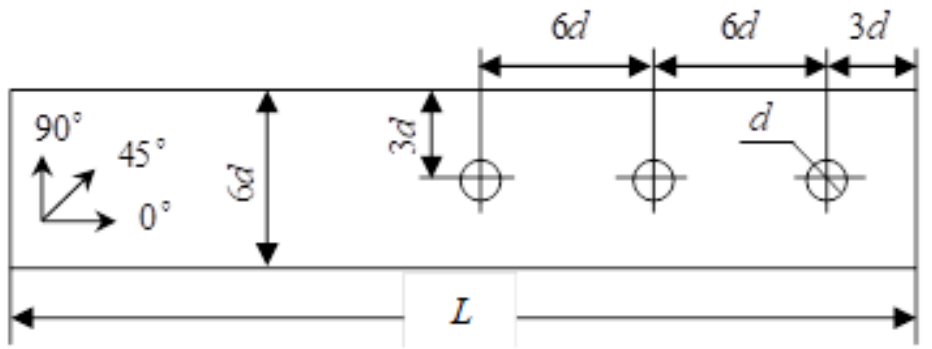

Figure 7

Size of the single-lap three-bolt composite joints [22].

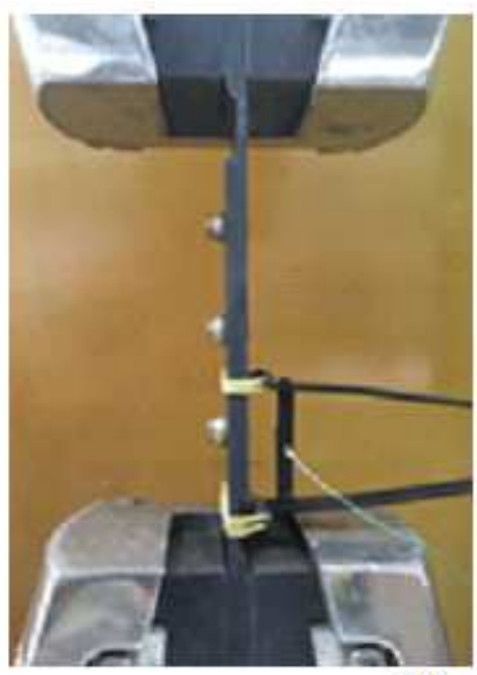

(a)

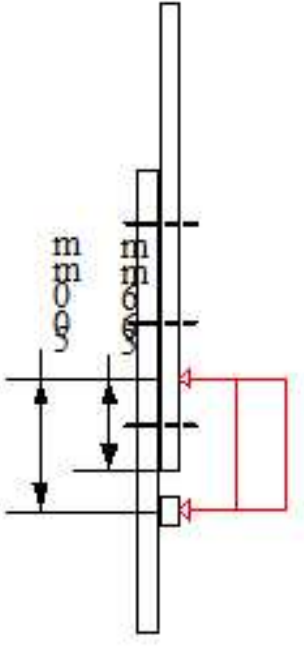

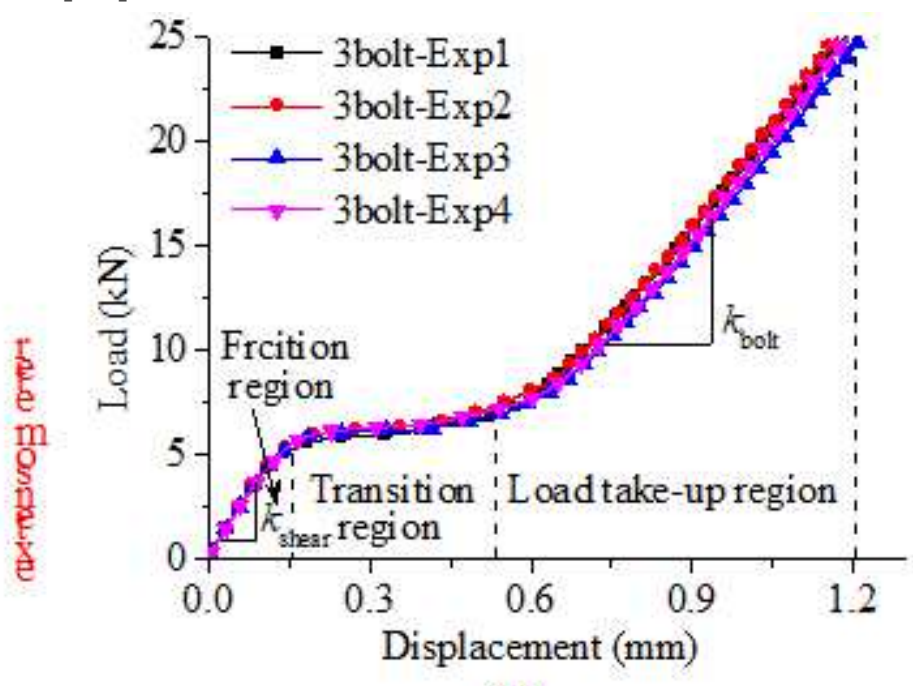

(b)

Figure 8

Experiment set-up and typical load-displacement response for single-lap three-bolt composite joints: (a) experiment set-up; (b) load-displacement curves. 


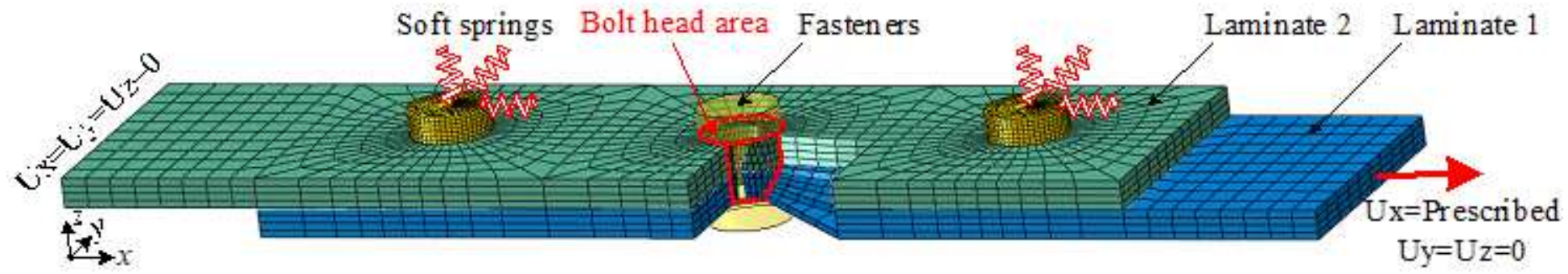

Figure 9

Finite element model of three-bolt composite joints.
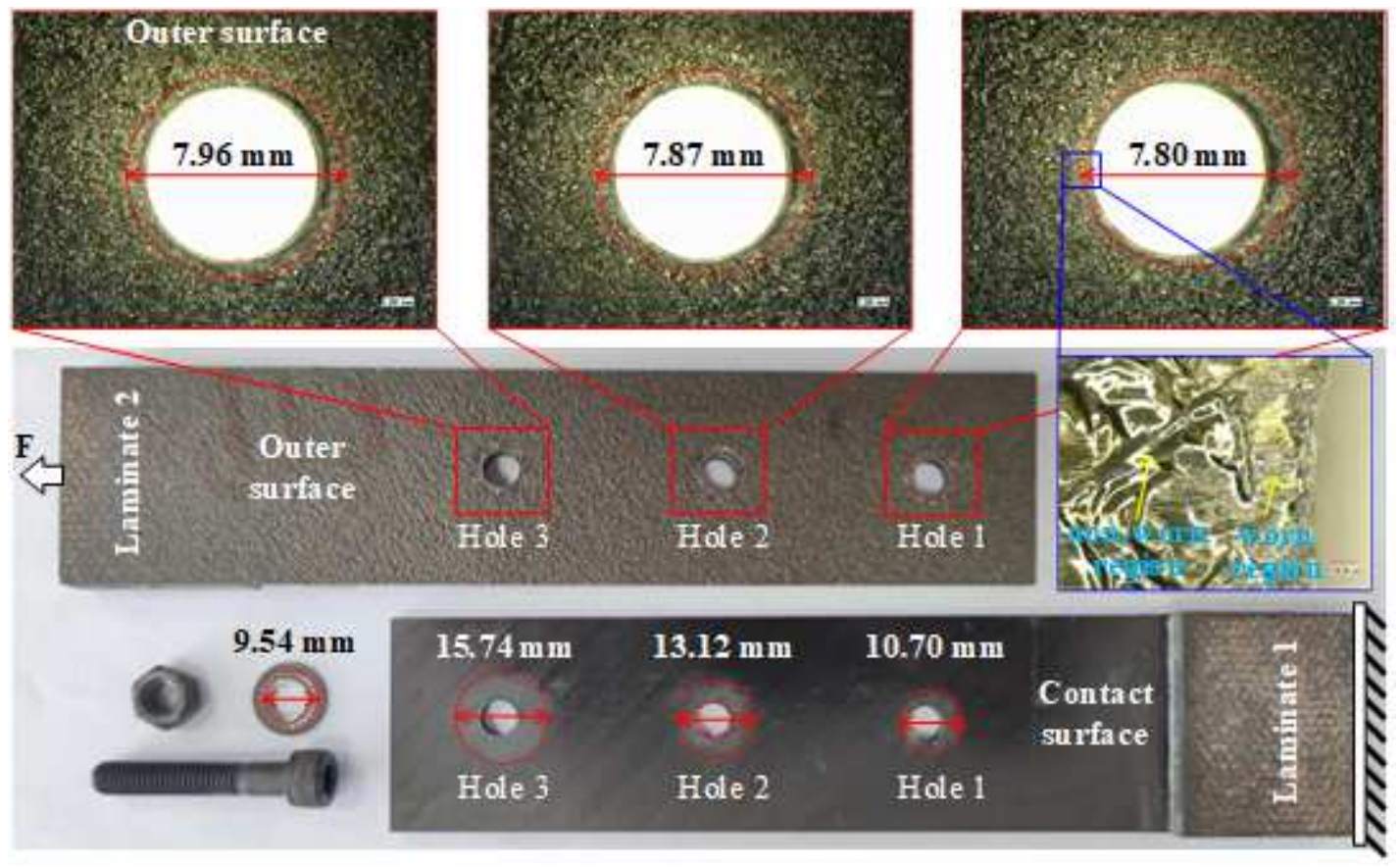

Figure 10

Surface profiles of the single-lap three-bolt composite joints after experiment.
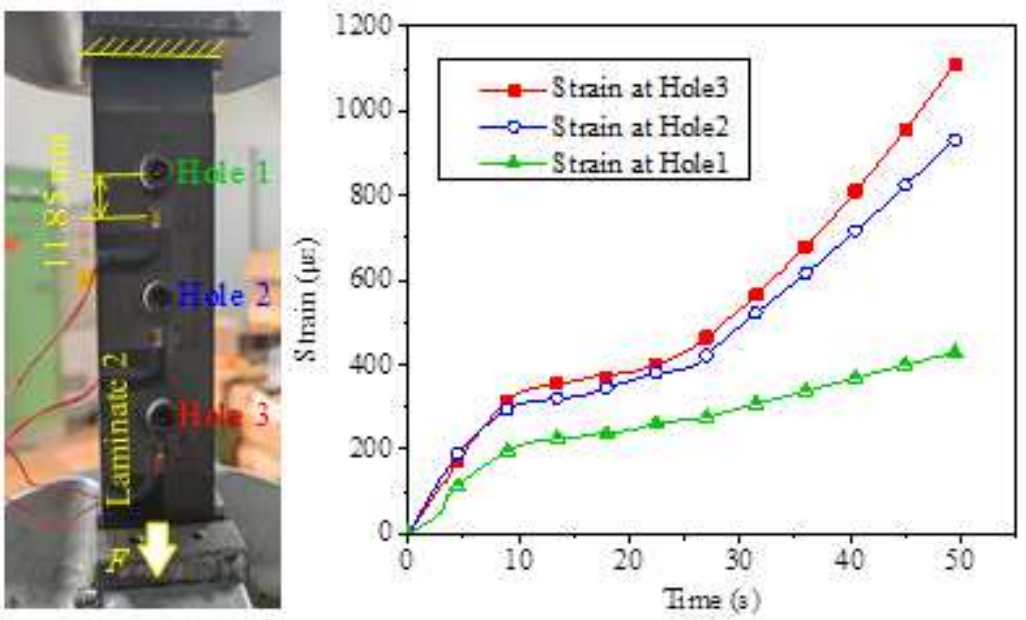

Figure 11 
Experimental set-up and strain-time curves of the single-lap three-bolt composite joints.

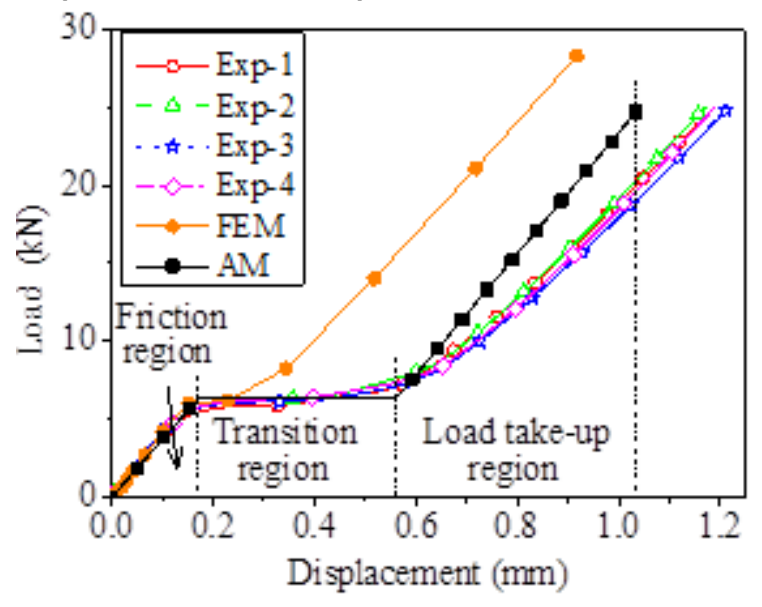

\section{Figure 12}

Model validation with experiments and FEM of the three-bolt joints without assembly gap.

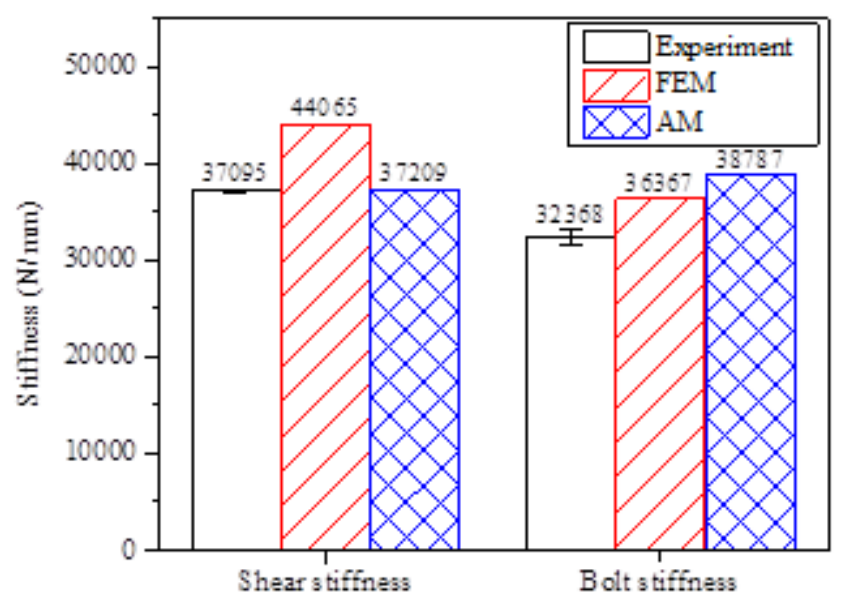

Figure 13

Shear stiffness comparison and bolt stiffness comparison among the experiments, FEM and analytical models. 
(a)

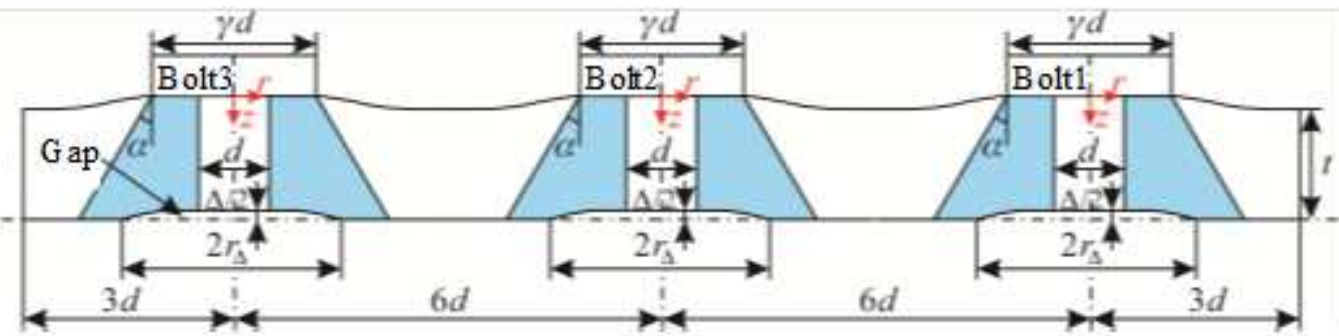

(b)

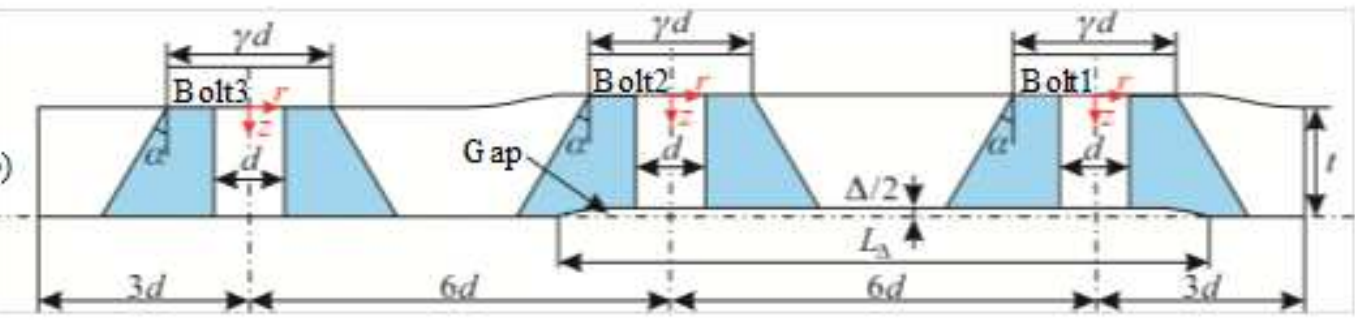

(c)

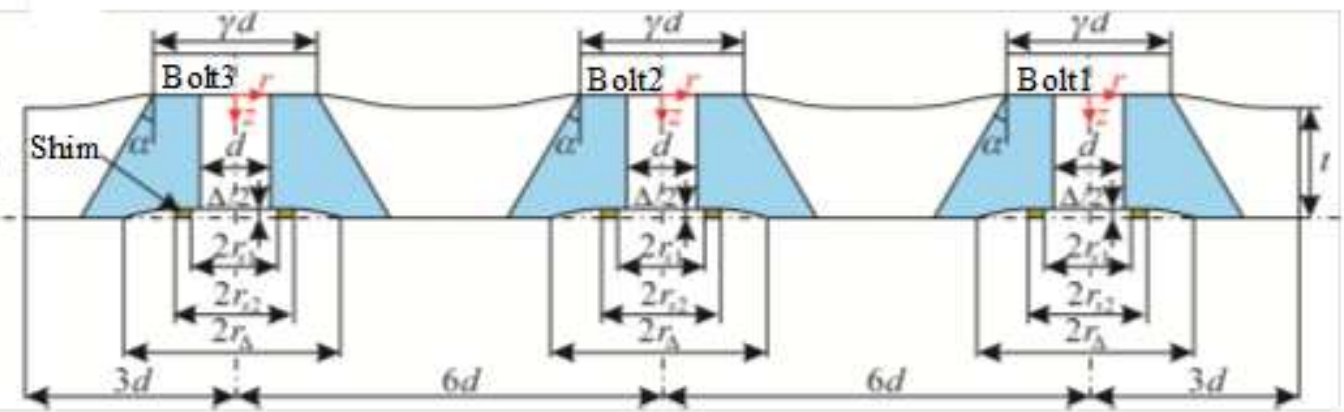

(d)

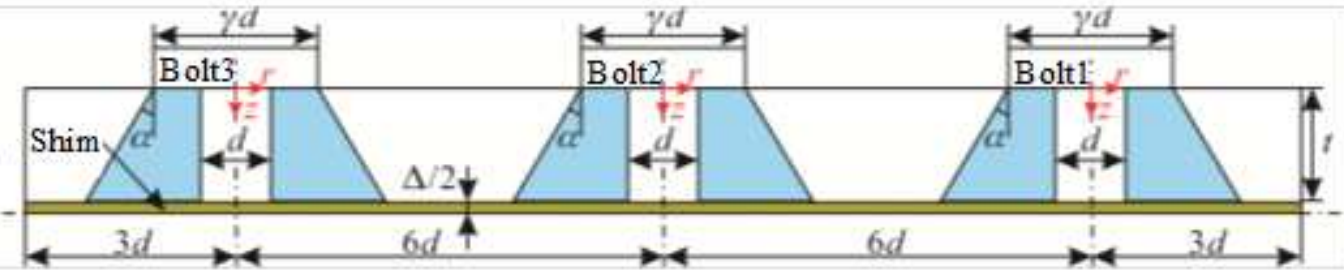

Figure 14

Four interested situations with different assembly gap and/or shims: (a) 'Gap A'; (b) 'Gap B'; (c) 'Shim A'; (d) 'Shim B'. 


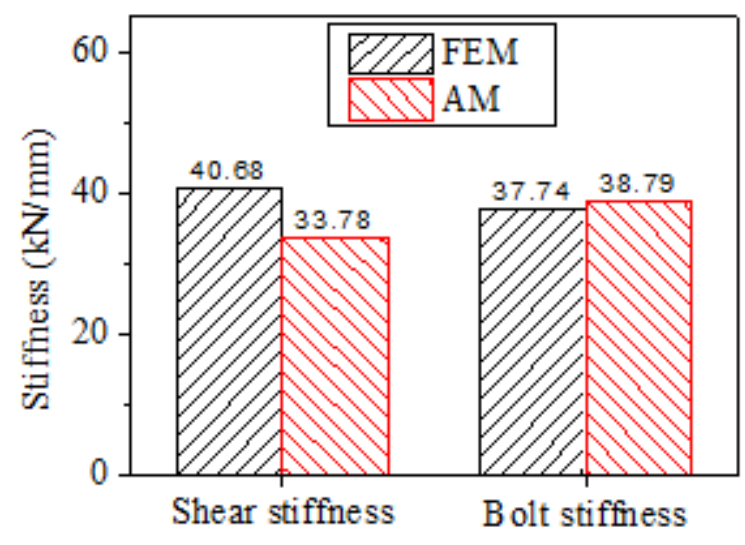

(a)

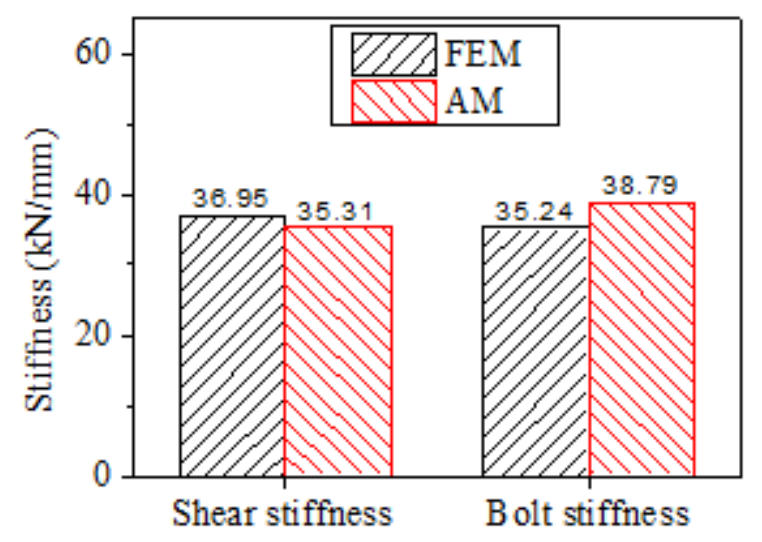

(c)

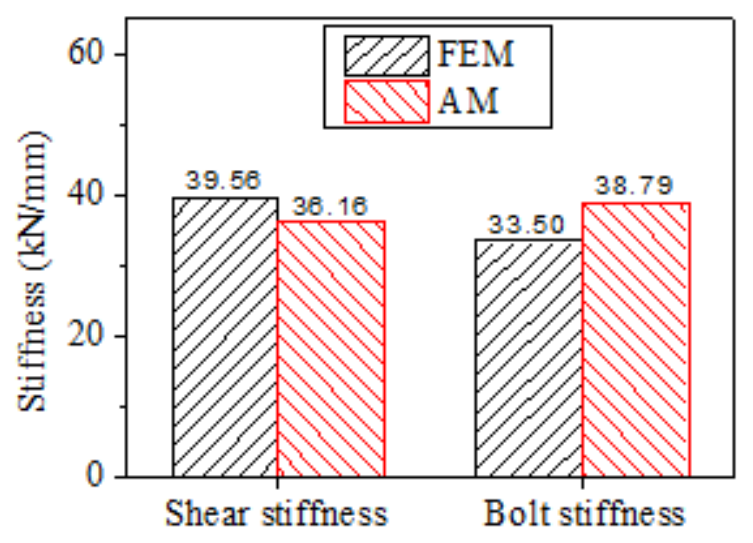

(b)

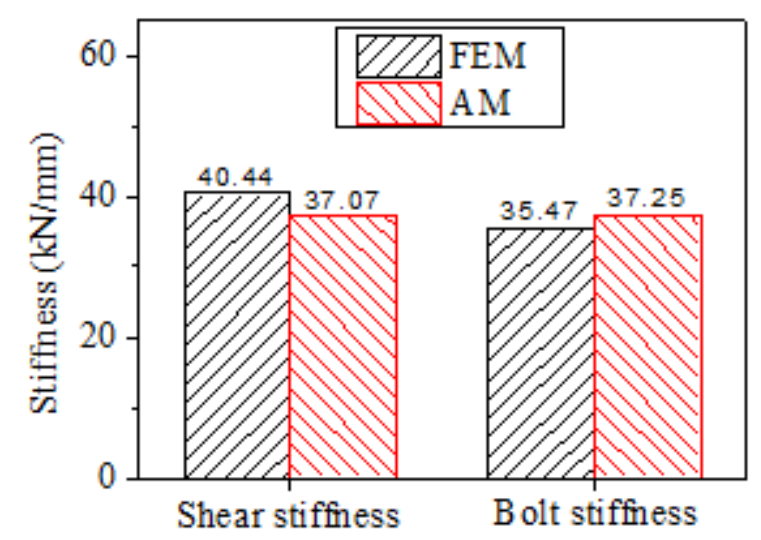

(d)

Figure 15

Shear stiffness and bolt stiffness results from the FEM and AM for four interested situations: (a) 'Gap A'; (b) 'Gap B'; (c) 'Shim A'; (d) 'Shim B'. 